\title{
Labor Market Effects of Demographic Shifts and Migration in OECD Countries*
}

\author{
Frédéric Docquier $^{a}$, Zovanga L. Kone ${ }^{b}$, Aaditya Mattoo $^{c}$, Caglar Ozden $^{c}$ \\ ${ }^{a}$ FNRS and IRES, Université catholique de Louvain (Belgium), and FERDI (France) \\ ${ }^{b}$ COMPAS, University of Oxford (United Kingdom) \\ ${ }^{c}$ Development Research Group, the World Bank (United States)
}

November 3, 2018

\begin{abstract}
The labor force of each industrial country is being shaped by three forces: ageing, education and migration. Drawing on a new database for the OECD countries and a standard analytical framework, this paper focuses on the relative and aggregate effects of these three forces on wages across different skill and age groups over the years 2000 to 2010. The variation in the age and educational structure of the labor force emerges as the dominant influence on wage changes. The impact is uniform and egalitarian: in almost all countries, the changes in the age and skill structure favor the low-skilled and hurt the highly skilled across age groups. Immigration plays a relatively minor role, except in a handful of open countries, like Australia and Canada, where it accentuates the wage-equalizing impact of ageing and education. Emigration is the only inegalitarian influence, especially in Ireland and a few Eastern European countries which have seen significant outflows of high-skilled labor to Western European Union countries.
\end{abstract}

Keywords: Ageing; Emigration; Immigration; OECD countries.

JEL codes: F22; J11; J22.

\footnotetext{
${ }^{*}$ We thank two anonymous referees for their helpful remarks. We are also grateful for comments from Costanza Biavaschi, Giovanni Peri, Hillel Rapoport, Michel Beine, Chris Parsons, Erhan Artuc, James Otterson and other participants at the 7th Annual Conference on Immigration in OECD Countries in Paris and the 10th International Migration and Development Conference in Clermont-Ferrand. The authors acknowledge financial support from the Knowledge for Change Program, the Research Support Budget and the Multidonor Trust Fund for Trade and Development of the World Bank. The findings in this paper do not necessarily represent the views of the World Bank's Board of Executive Directors or the governments they represent. Any errors or omissions are the authors' responsibility.
} 


\section{Introduction}

The labor force of each industrial country is being shaped by three forces: ageing, education and migration. Ageing is a powerful, gradual process that evokes concern but little policy action. Immigration is blamed for the predicament of the low-skilled and is provoking a political backlash. Education is viewed as a panacea to which access is unequally distributed.

Yet one question has not been addressed: what are the relative and combined effects of these three forces on wages across different skill and age groups? This is an especially pertinent question as increased wage inequality across skill and age groups dominates the political and academic debate. This paper addresses the question using data for the OECD countries on the age, education and place of birth of individuals across two decades (Arslan et al., 2015). The impact on wages is derived using a simple model of the economy that allows for imperfect substitutability between the skilled and the unskilled, old and young, and natives and foreign born. The change in the age and skill structure of labor forces emerges as the dominant force influencing relative wage changes, with migration playing a smaller role in most countries.

The database helps us to measure how the education and age structure of the populations have changed between the years 2000 and 2010. Populations across the OECD have become older and more skilled. Figure 1 shows the changes in the shares of four groups in the native working age population: young low-skilled, young high-skilled, old low-skilled and old high-skilled. The most striking feature is the decline across all countries in the share of the young low-skilled workers (blue bars). This decline is matched by the increase in the share of the skilled, both young (orange) and old (yellow), across almost all countries. Finally, in a majority of countries, there has also been an increase in the share of the old low-skilled (grey). There are exceptions to this pattern, notably Japan, where the share of the old low-skilled workers has actually declined.

Migration, especially from lower to higher income countries, is another force shaping labor markets in both sending and receiving countries. The number of migrants grew from 2.9 percent of the world population in 2000 to 3.3 percent in 2010. (World Bank, 2018). Migrants now come from an increasing number of countries, but still move to fewer destinations which are predominantly high-income OECD countries (Czaika and de Haas, 2014). Figure 2 depicts changes in the shares of the four age-education groups among the immigrant working age population in each OECD destination country. The patterns are similar to those for natives. Shares of the young low-skilled immigrants are declining while shares of the high-skilled are increasing. There are several exceptions, notably Belgium, to these patterns. ${ }^{1}$ Similar patterns are observed when we explore the changes in the age

\footnotetext{
${ }^{1} \mathrm{We}$ also see that some of the Eastern European countries and Japan are outliers, but they have a very small number of migrants and small changes in their numbers lead to large swings in shares.
} 
and education of emigrants from the OECD countries.

Imperfect substitutability in production between low-skilled and college educated, old and young, native and foreign-born workers is the source of heterogenous impact of these changes in the labor force composition. If workers of different ages were perfectly substitutable, ageing would have no implications for wages except when workers retired. However, available empirical evidence suggests that workers of different ages are imperfect substitutes (Card and Lemieux, 2001). Evidence, mainly from the USA and the UK, also suggests that immigrants and natives are imperfect substitutes across age-education cells (see Ottaviano and Peri, 2012, and Manacorda et al., 2012). It might take some time for migrants to acquire the language skills and human capital specific to the destination labor markets. Immigrants tend to concentrate in different sectors or occupations because of diaspora networks, information constraints and historical accidents. Therefore, the effects of immigration on the wages of natives depend not only on the age-education distribution of immigrants but also on their respective elasticities of substitution with natives.

We use a CES production function with multiple nests and consider an economy that produces a homogenous good using eight types of labor: (1) a given worker is either high-skilled or low-skilled; (2) within each of these two categories, a worker is either old or young; and (3) finally, within each of the resulting four categories, a worker is either native-born or foreign-born. A nested CES production function with a homogenous good has been widely used in labor economics to examine the substitutability between workers of different ages and to gauge the implication of immigration for the labor market outcomes of natives. For example, Card and Lemieux (2001) use a similar framework to demonstrate that the decline in the rate of growth of the college educated workers explains the widening gap in the wages of college and non-college educated groups over the last three decades of the 20th century in Canada, the UK, and the USA. Other examples of resdarch using a smilar approach include Borjas (2003), Card (2009), Manacorda et al. (2012) and Ottaviano and Peri (2012).

Our main finding is that the change in the age and skill structure of the workforce is the dominant supply-side factor on wage changes. The impact is quite uniform and egalitarian: in almost all countries, the changes in the age and skill structure actually favor the lowskilled and hurt the highly skilled across all age groups. However, the relative impact of ageing and migration differs across countries. The OECD countries can be divided into three broad groups. In most of Western Europe, Japan and the United States, ageing and changes in the stock of skills, account for most of the changes in wages, and migration plays a marginal role. In the Anglo-Saxon countries (Australia, Canada, New Zealand, the United Kingdom) and Switzerland, which have relatively liberal and skill-biased migration policies, immigration accentuates the impact of ageing on wages. The impact of ageing 
is partially offset by emigration in countries which have seen significant labor outflows, such as Ireland and certain Eastern European countries (the Czech Republic,the Slovak Republic, Hungary and Poland) that now have access to Western European labor markets.

We examine the robustness of these results to four extensions of our baseline model. First, changes to the elasticities of subsitution within different nests do not qualitatively change our results. For example, greater substitutability between high and low skilled workers only dampens the divergent impact of changes in the age and skill structure the high skilled lose less and the low skilled gain less. Second, allowing for involuntary unemployment and introducing unemployment benefits also leaves the basic results unchanged for all countries except in a few cases where unemployment rates are high (like Spain) and where unemployment benefits are generous (like Switzerland). Third, if we were to assume that capital stock is fixed rather than mobile between countries, wages would be lower in most countries, but the relative effects on different groups of workers do not change. With mobile capital, most OECD countries experience capital inflows to match increases in their stocks of composite labor which leads to higher wages. Finally, sufficiently strong skill-biased technological change can offset the adverse effects on skilled wages of increased skill endowments. This observation can help to reconcile the narrowing of wage gaps predicted by our model with the increasing skill premium observed in many countries.

The observed shifts in the age structure of populations have typically provoked concerns about economic growth and fiscal policy sustainability, rather than labor market outcomes. (see Leers et al, 2003; Blake and Mayhew, 2006; Bloom et al, 2010; Lee, 2014; Mahlberg et al., 2013; Sheiner, 2014). However, our study relates to the literature which identifies a link between demographic changes in the labor force and the growth of wage inequalities observed over the last decades. This literature started with a simple demand and supply perspective, whereby the relative increase (decrease) in the share of a particular group of workers in the labor supply decreases (increases) their relative wages (Freemann, 1979; Katz and Murphy, 1992; Murphy and Welch, 1992; Card and Lemieux, 2001). Later work emphasized the role of demand-side factors, in particular Skill-Biased Technological Change (SBTC) which is said to have favored skilled workers and been the main causes of wage inequalities (Acemoglu, 2002; Autor et al., 2003; 2008). The debate continued with other papers suggesting that changes in institutional settings, such as the decline in the real value of the legal minimum wage and the bargaining power of trade unions, explain a significant portion of the observed wage inequalities (Bound and Johnson, 1992; Lee, 1999; Card and DiNardo, 2002). Lemieux (2008) and Autor et al. (2008) provide thorough reviews of the literature on the topic, although with competing positions. Our contribution to this debate on the causes of the rising wage inequality is in exploring the role of the striking changes in the workforce composition due to age- 
ing, educational upgrading and international labor mobility. While we assume a world where technology and institutions are not changing in our main analysis, we relax these assumptions and explore how they interact with demographic changes.

The second strand of the literature pertains to the impact of immigration on the labor market outcomes of natives. Papers examining the impact of immigration on the wages of natives using a framework similar to ours include Ottaviano and Peri (2012) in the context of the USA, and Manacorda et al (2012) and Dustmann et al (2013) in the case of the UK. These papers only focus on immigration, although emigration is particularly high in some OECD countries such as Ireland and Poland. Docquier et al. (2014), referred to as DOP hereafter and the closest study to ours, fills this gap by looking at the joint effect of emigration and immigration on the labor market outcomes of high-skilled and low-skilled natives in OECD countries between 1990 and 2000.

Our study differs from DOP along several dimensions. Whereas their focus is entirely on the labor market changes due to immigration and emigration, we analyze the effects of ageing, educational improvements, emigration and immigration jointly. For this purpose, we introduce the age dimension into the model via imperfect substitution between the young and old workers in production. We also exploit recent data from the 2000 and 2010 censuses which contain detailed information on the age-education-nativity distribution of the workforce across OECD countries.

The rest of the paper is organized as follows. Section 2 presents the aggregate production and labor supply framework, and analytically derives the wage effects of ageing, education and migration shocks. Section 3 describes the construction of our data set and provides summary statistics of the labor force, migrant data, and changes in their age and educational composition. This section also presents the discussion of the main parameter values used in the analysis. Section 4 discusses the simulated wage effects of ageing, educational changes and migration, using our model and the range of parameters available from the literature. Section 5 examines the consequences of relaxing some of the assumptions we make. Section 6 concludes the paper.

\section{The analytic model}

We construct a static aggregate model that endogenizes the effect of the changes in the education, age, immigrant and emigrant composition of the labor force on the wage levels of native (non-migrant) citizens. Workers differ by their migration status, educational attainment (i.e. skills), and age group and have heterogeneous labor force participation preferences. In terms of migration status, we distinguish between the native-born and the foreign-born workers, which are denoted by $M=(N, F)$. In terms of educational attainment, we follow the literature in labor economics (Freeman, 1979; Katz and Murphy, 
1992; Card and Lemieux, 2001), and distinguish between workers with college education (or high-skilled) and the less educated (or low-skilled), denoted by $S=(H, L)$. Finally, in terms of age groups, we split the labor force between young (25-44 years of age) and old (45-64 years of age) workers, denoted by $A=(Y, O)$. We describe below the production technology that determines the labor demand in the economy, the preferences that govern the labor supply decisions of workers, and the competitive labor market equilibrium of our benchmark model. Variants of the benchmark model are described at the end of the section.

\subsection{Aggregate production function}

In each country, output $(y)$ is produced using a CRS (constant returns to scale), CobbDouglas function of physical capital $(k)$ and composite labor $(q)$ :

$$
y=\widetilde{A} k^{\alpha} q^{1-\alpha}=\widetilde{A}\left(\frac{k}{q}\right)^{\alpha} q
$$

where $\widetilde{A}$ is a scale parameter capturing the total factor productivity (TFP), and $\alpha$ is the share of capital in total income.

Assuming capital is internationally mobile and each country is too small to affect the world capital markets, the price of capital $(R)$ is equalized across countries and is taken to be fixed. ${ }^{2}$ Setting the marginal productivity of capital equal to its price determines the ratio of capital per worker in the economy:

$$
\frac{k}{q}=\left(\frac{\alpha \widetilde{A}}{R}\right)^{\frac{1}{1-\alpha}} .
$$

Substituting Equation (2) into Equation (1) allows us to write the aggregate output as a linear function of the aggregate labor composite $q$ :

$$
y=A q
$$

where $A=\widetilde{A}^{\frac{1}{1-\alpha}}\left(\frac{\alpha}{R}\right)^{\frac{\alpha}{1-\alpha}}$ is the modified TFP term. A fraction $\alpha$ of total output serves to remunerate physical capital, while labor compensation accounts for the remaining

\footnotetext{
${ }^{2}$ In the extensions section, we add a simulation where the capital stock is fixed and we discuss the changes in the results.
} 
fraction of $(1-\alpha)$. In other words, national wage bill equals $(1-\alpha) y$.

In line with the extensive literature that explores the impact of immigration on labor market outcomes of natives (see Borjas, 2003; Card, 2009; Ottaviano and Peri, 2012; Manacorda et al., 2012; DOP, 2014), we assume that the aggregate labor composite $q$ can be modeled as a nested CES (constant elasticity of substitution) function of different worker types. ${ }^{3}$ We consider a CES function comprising three nests and eight types of workers differentiated by their education (or skill) levels $(S)$, age $(A)$, and migration status $(M)$. The total population of any type of worker $S A M$ in a country is exogenous and denoted by $Q_{S A M}$. This is different from the level of employment, denoted by $q_{S A M}$ and determined by a labor supply function as discussed below. This structure allows us to examine the changes in wage levels of different types of native workers, due to the changes in the education, age and migration levels of these distinct eight subgroups of the labor force. Our nest structure is illustrated by Figure 3.

In the first nest, we assume that labor composite $q$ is a CES combination of high-skilled and low-skilled labor:

$$
q=\left(\frac{\Gamma_{S}}{1+\Gamma_{S}} q_{H}^{\frac{\sigma_{S}-1}{\sigma_{S}}}+\frac{1}{1+\Gamma_{S}} q_{L}^{\frac{\sigma_{S}-1}{\sigma_{S}}}\right)^{\frac{\sigma_{S}}{\sigma_{S}-1}}
$$

where $q_{H}$ and $q_{L}$ denote the composite employment levels of high-skilled and lowskilled workers, respectively. $\Gamma_{S}$ is a parameter determining the relative productivity levels of these two skill groups and $\sigma_{S}$ is the elasticity of substitution between them. In our benchmark model, we treat the productivity parameter $\Gamma_{S}$ as exogenous. In the robustness analysis section, we will endogenize it.

Our framework does not make a distinction between workers with a college degree and those with a higher level of qualification (such as a master's degree), or among those with and without a high-school diplomas. These simplifying assumptions are reasonable in light of the empirical evidence showing a high degree of substitutability between workers with a high-school diploma and those without that diploma, but a very low degree of substitutability between workers with and those without tertiary education (Goldin and Katz, 2008; Card, 2009; and Peri, 2012).

Empirical evidence suggests an imperfect degree of substitution between older and younger workers (Card and Lemieux, 2001) within each education group. If younger workers and older workers were perfectly substitutable, the overall measure of aggregate labor in each education group would simply be the sum of these two types of workers. In the presence of imperfect substitution, $q_{H}$ and $q_{L}$ are each assumed to be nested CES

\footnotetext{
${ }^{3}$ The CES function is also used in the labor economics literature to examine the drivers of wage inequality (Katz and Murphy, 1992, Murphy and Welch, 1992; Card and Lemieux, 2001; Acemoglu,2002).
} 
functions of younger workers and older workers:

$$
q_{S}=\left(\frac{\Gamma_{S A}}{1+\Gamma_{S A}} q_{S Y}^{\frac{\sigma_{A}-1}{\sigma_{A}}}+\frac{1}{1+\Gamma_{S A}} q_{S O}^{\frac{\sigma_{A}-1}{\sigma_{A}}}\right)^{\frac{\sigma_{A}}{\sigma_{A}-1}} \forall S,
$$

In this expression $q_{S Y}$ is the number of employed younger workers of skill group $S \in$ $\{H, L\}$ and $q_{S O}$ is the corresponding number of older workers. Similar to the earlier nest, $\Gamma_{S A}$ is a parameter governing the relative productivity levels of the young and the old in the skill group $S$ which allows $\Gamma_{S A}$ to be skill-specific. And $\sigma_{A}$ is the elasticity of substitution between workers across different age groups. We assume these elasticities are identical within each skill group.

The final distinction in the composition of labor is the separation of workers into native and immigrant groups within each of the four skill-age group cells. This is motivated by the literature that explores the degree of substitutability between immigrants and natives in the local labor markets (Card, 2009; Manacorda et al., 2012; Ottaviano and Peri, 2012). There are numerous reasons for this imperfect substitutability, such as the time it takes for immigrants to become familiar with the host country's norms and laws or to acquire human capital and language skills specific to the destination labor market (Bleakley and Chin, 2004; Amuedo-Dorantes and De la Rica, 2007; Gagliardi and Lemos, 2016; and Chiswick, 1978). Additionally, there is nascent empirical evidence showing that immigrants and natives are employed in relatively different occupations/industries due to the role of diaspora networks, information constraints, specific skills or simply historical accidents (Peri and Sparber, 2009; Patel and Vella, 2013). Therefore, for each group of workers of education-age type, we have

$$
q_{S A}=\left(\frac{\Gamma_{S A M}}{1+\Gamma_{S A M}} q_{S A N}^{\frac{\sigma_{M}-1}{\sigma_{M}}}+\frac{1}{1+\Gamma_{S A M}} q_{S A F}^{\frac{\sigma_{M}-1}{\sigma_{M}}}\right)^{\frac{\sigma_{M}}{\sigma_{M}-1}} \forall S, A
$$

where $q_{S A N}$ represents the employment of native workers of type $S A \in\{H Y, L Y, H O, L O\}$

and $q_{S A F}$ represents the corresponding employment of foreign-born immigrants. $\Gamma_{S A M}$ is again a parameter governing the relative productivity of natives and immigrants in the group $S A ; \sigma_{M}$ is the elasticity of substitution between immigrants and natives.

\subsection{Labor demand}

The model assumes each country is a single labor market with eight types of workers identified by three indices, $S A M$. Recall that $S \in\{H, L\}$ denotes the skill level, $A \in$ 
$\{Y, O\}$ denotes the age group and $M \in\{N, F\}$ denotes the migration status (native or foreign-born) of each worker. The representative firm maximizes profits and chooses the level of employment that equalizes the marginal productivity of labor to its price. The marginal productivity of each type of worker, $S A M$, is obtained by substituting (4), (5) and (6) into (3) and then by differentiating the expression with respect to $q_{S A M}$. The profit maximization condition can be expressed as:

$$
w_{S A M}=A(1-\alpha) \frac{\partial q}{\partial q_{S}} \frac{\partial q_{S}}{\partial q_{S A}} \frac{\partial q_{S A}}{\partial q_{S A M}} \quad \forall S, A, M
$$

As an example, the optimal employment condition for college-educated young natives, labeled as $H Y N$, satisfies:

$$
w_{H Y N}=A(1-\alpha) \frac{\Gamma_{S}}{1+\Gamma_{S}}\left(\frac{q}{q_{H}}\right)^{1 / \sigma_{S}} \frac{\Gamma_{S A}}{1+\Gamma_{S A}}\left(\frac{q_{H}}{q_{H Y}}\right)^{1 / \sigma_{A}} \frac{\Gamma_{S A M}}{1+\Gamma_{S A M}}\left(\frac{q_{H Y}}{q_{H Y N}}\right)^{1 / \sigma_{M}} .
$$

Eq. (7) defines a system of eight nonlinear profit-maximization conditions (one for each labor type), which implicitly determines the demand for all types of labor as a function $D$ of the vector of wage rates:

$$
\mathbf{q}=D(\mathbf{w})
$$

where $\mathbf{q}$ is the vector of optimal levels of employment, and $\mathbf{w}$ is the wage vector.

\subsection{Labor supply}

Labor supply of workers is determined through the work-leisure tradeoff in the benchmark model. We assume there is no involuntary unemployment for the moment, but we will relax this assumption in the robustness analysis. Each worker of type $S A M$ allocates his (or her) unit of time between $l_{S A M}$ units of work and $1-l_{S A M}$ units of leisure. This allocation maximizes an instant utility function, which depends positively on consumption, $c_{S A M}$, and negatively on the amount of labor supplied, $l_{S A M}$ :

$$
U_{S A M}=\rho_{S A M}^{c} c_{S A M}^{\delta}-\rho_{S A M}^{l} l_{S A M}^{\eta}
$$

The preference parameters $\rho_{S A M}^{c}$ and $\rho_{S A M}^{l}$ vary across labor groups, whereas, for simplicity, the elasticities $\delta$ and $\eta$ are assumed to be identical across all types of work- 
ers. Furthermore, we assume that individuals consume all their labor income, such that $c_{S A M}=l_{S A M} w_{S A M} \cdot{ }^{4}$ Substituting this constraint into equation (9) and maximizing with respect to $l_{S A M}$ leads to

$$
l_{S A M}=\phi_{S A M} w_{S A M}^{\gamma}
$$

where the parameter $\phi_{S A M}$, which equals $\left[\frac{\delta \rho_{S A M}^{c}}{\eta \rho_{S A M}^{l}}\right]^{\frac{1}{\eta-\delta}}$, varies across labor groups. As a result, the model allows us to capture differences in labor force participation rates across skill and age groups, and across natives and immigrants. These differences can be due to the heterogeneity in the disutility of labor, in the preferences for consumption, in cultural traits or in social norms. In addition, $\gamma=\frac{\delta}{\eta-\delta}$ is the elasticity of labor supply to income, which is assumed to be positive and common across labor groups.

The aggregate labor supply of workers of type $S A M$ is obtained by multiplying (10) with the population size, $Q_{S A M}$, of that type:

$$
\bar{q}_{S A M}=l_{S A M} Q_{S A M}=\phi_{S A M} w_{S A M}^{\gamma} Q_{S A M} \quad \forall S, A, M,
$$

We can equivalently express this equation in vector format:

$$
\overline{\mathbf{q}}=G(\mathbf{w})
$$

\subsection{Labor market equilibrium}

A competitive labor market equilibrium is defined as the following:

Definition For a set of common elasticities $\left\{\sigma_{S}, \sigma_{A}, \sigma_{M}, \gamma\right\}$, a set of group-specific parameters $\left\{\Gamma_{S}, \Gamma_{S A}, \Gamma_{S A M}\right\}$, and for a given composition of the labor force $\left\{Q_{S A M}\right\}$, the labor market equilibrium is a set of endogenous employment levels and wage rates $\left\{q_{S A M}, \bar{q}_{S A M}, w_{S A M}\right\}$ such that the optimal labor demand conditions (8) hold, the optimal labor supply conditions (12) hold, and the labor market clears in all groups, $q_{S A M}=$ $\bar{q}_{S A M} \forall S, A, M$.

Once the competitive equilibrium is computed, the model can be used to quantify the effect of exogenous labor supply shocks on employment levels and wage rates of each labor type.

There are four main sources of changes in the labor force: (1) changes in the number of immigrants in each age-skill type as they enter/exit the country; (2) changes in the number of natives of each age-skill type due to emigration; (3) changes in the number of

\footnotetext{
${ }^{4}$ Allowing consumption to be a constant share of labor income does not alter the implications
} 
natives of each age-skill type due to the changes in education levels; and (4) changes in the number of natives of each age-skill type due to ageing. We should note that it is not simple to separate the ageing effect (4) from the changes in the education levels (3) in the data - we nevertheless undertake this exercise later in Appendix C. Younger cohorts tend to have higher education levels, leading to increased education levels as time passes. Ageing occurs as the relative share of the older group in the labor force increases. This is due to each successive cohort of natives having fewer number of people, mainly due to demographic reasons such as declining fertility rates.

In equilibrium, the wages and employment levels of workers of each type adjust as they respond to these demographic changes. For example, the ratios of the wages between natives and immigrants, between young and old workers, or between high-skilled and low-skilled workers are given by:

$$
\begin{aligned}
\frac{w_{S A N}}{w_{S A F}} & =\Gamma_{S A M}\left(\frac{q_{S A N}}{q_{S A F}}\right)^{-1 / \sigma_{M}} \forall S, A \\
\frac{w_{S Y}}{w_{S O}} & =\Gamma_{S A}\left(\frac{q_{S Y}}{q_{S O}}\right)^{-1 / \sigma_{A}} \forall S \\
\frac{w_{H}}{w_{L}} & =\Gamma_{S}\left(\frac{q_{H}}{q_{L}}\right)^{-1 / \sigma_{S}}
\end{aligned}
$$

\subsection{Alternative labor market structures}

Our benchmark model assumes that unemployment is voluntary and linked to the endogenous labor force participation decision of workers. We account for the difference in employment rates between groups by introducing heterogeneity in the preference parameters in the utility functions in equation (9). Labor force data reveal that differences in employment rates are mainly governed by differences in participation rates (Burzynski et al., 2018). This motivates our choice to endogenize participation rates and disregard involuntary unemployment. However, as a robustness check, we relax certain assumptions and use an alternative specification, which involves smaller responses to socio-demographic changes.

We first assume that unemployment can be partly involuntary. At each moment in time, active workers face exogenous job separation and matching rates, implying that they spend an exogenous fraction $\left(1-u_{S A M}\right)$ of their active time in employment, and the remaining fraction $u_{S A M}$ in unemployment while searching for a job. ${ }^{5}$ Working and searching for a job induce the same level of disutility. Job separation and matching rates differ across groups, implying that unemployment rates are group-specific.

\footnotetext{
${ }^{5} \mathrm{~A}$ more realistic modelling of the unemployment response to socio-demographic shocks can be found in Chassamboulli and Palivos (2014) or Battisti et al. (2018).
} 
Our next assumption is that, during each unemployment spell, active workers receive unemployment benefits that are assumed to be equal to a fraction $\beta<1$ of the average wage rate of the economy $(\bar{w})$. This simplifying assumption implies that all unemployed workers receive the same amount of unemployment benefits. In other words, the national unemployment insurance scheme is redistributive and the fraction $\beta$ captures its generosity (i.e., the unemployment replacement rate). The budget constraint of the individual becomes $c_{S A M}=l_{S A M} \varpi_{S A M}$, where $\varpi_{S A M}=w_{S A M}\left(1-u_{S A M}+\beta u_{S A M} w / w_{S A M}\right)$ represents the average income per active hour, i.e. per hour supplied on the labor market (a weighted average of net wages and unemployment benefits). ${ }^{6}$ Hence, the aggregate labor supply of workers of type $S A M$ is now given by

$$
\bar{q}_{S A M}=\phi_{S A M} \varpi_{S A M}^{\gamma} Q_{S A M} \quad \forall S, A, M
$$

and we now replace the condition $q_{S A M}=\bar{q}_{S A M}$ in Definition 1 by $q_{S A M}=\bar{q}_{S A M}(1-$ $\left.u_{S A M}\right)$. The average income per active hour, $\varpi_{S A M}$, is less responsive to socio-demographic shocks than the wage rate, $w_{S A M}$. Compared with the benchmark model, this specification with redistributive unemployment benefits involves lower levels of labor supply responses.

\subsection{Capital mobility}

Capital is assumed to be internationally mobile in the benchmark model and we consider this specification as the most relevant for the long-term analysis. As a robustness check, we consider a scenario where the capital stock in the economy is fixed and explore the implications of this assumption on wages as labor market composition evolves over time.

Ortega and Peri (2014) find that capital adjustment processes are quite rapid in open economies. An inflow of migrants increases employment level one-for-one in the local labor market and capital stocks in the short term (i.e. within one year), leaving the capital/labor ratio unchanged, in line with Eq. (2). However, in the short-run or depending on certain rigidities in the capital markets, the available capital stock can be considered to be fixed at $\bar{k}$. In this case, variations in the quantity of labor would affect the level of capital available per worker and, hence, labor productivity and equilibrium wages. This requires us to include an additional term, $(\bar{k} / q)^{\alpha}$, in Eq.(7), which then becomes:

$$
w_{S A M}=A(1-\alpha)\left(\frac{\bar{k}}{q}\right)^{\alpha} \frac{\partial q}{\partial q_{S}} \frac{\partial q_{S}}{\partial q_{S A}} \frac{\partial q_{S A}}{\partial q_{S A M}} \quad \forall S, A, M
$$

This expression implies that, if the aggregate labor composite changes from $q$ to $q^{\prime}$, the new wage rates are now multiplied by $\left(q^{\prime} / q\right)^{-\alpha}$. Besides the standard substitution and

\footnotetext{
${ }^{6}$ Assuming a non-redistributive unemployment insurance scheme (i.e., unemployment benefit equal to $\left.\beta w_{S A M}\right), \varpi_{S A M}$ would be proportional to $w_{S A M}$. The (relative) wage and labor market participation responses to socio-demographic shocks would be identical to those obtained in the benchmark model.
} 
complementarity forces, an increase in the aggregate labor composite reduces the level of capital per worker as well as the wage rates for all labor groups.

\subsection{Technological changes}

Another important assumption in the baseline scenario is that we treat the state of the technology as exogenous. As an extension, we analyze a specification with endogenous TFP and directed technical changes. Most importantly, in this specification, technology parameters change as the level and ratio of the high-skilled workers in the labor market changes.

In order to account for the aggregate TFP effect, we first consider a simple Lucastype, aggregate externality (see Lucas, 1988) and assume that the scale of the total factor productivity (TFP) is a concave function of the skill-ratio in the labor force. This externality captures the fact that college-educated workers facilitate innovation and the adoption of advanced technologies. So here, we assume that:

$$
A=A_{0}\left(\frac{q_{H}}{q_{L}}\right)^{\epsilon} .
$$

where $A_{0}$ is a scale factor and $\epsilon$ is the elasticity of TFP to aggregate schooling levels.

As for skill-biased technical changes, we assume the relative productivity of collegeeducated workers increases as technology improves, especially in the nonagricultural sector (Acemoglu, 2002; Restuccia and Vandenbroucke, 2013). Other supportive evidence includes Autor et al. (2003) who show that computerization is associated with lower relative industry demand for routine manual and cognitive tasks, and higher relative demand for nonroutine cognitive tasks. As such, the observed relative demand shift would favor college versus non-college educated labor. This implies

$$
\Gamma_{S}=\Gamma_{0}\left(\frac{q_{H}}{q_{L}}\right)^{\kappa}
$$

where $\Gamma_{0}$ is a scale factor and $\kappa$ governs the intensity of the skill-biased technical change. This expression implies that the productivity parameter in equation (15) is no longer fixed but needs to be modified to account for directed technical change.

\section{Data and parameterization}

Our model is parameterized to match the labor market characteristics of OECD member countries in the year 2010, and the socio-demographic changes that have taken place between 2000 and 2010. This section describes the data sources used and discusses the calibration strategy. 


\subsection{Labor force data}

Our main data source is the Database on Immigrants in OECD countries (DIOC), compiled jointly by the OECD and the World Bank. The database is the output of a project with the purpose of compiling highly standardized population census and register data on immigrants and natives in OECD countries, based on the 2000/01 census rounds. It was subsequently extended to include a large number of non-OECD countries and the extension is referred to as DIOC-E. The 2010 DIOC dataset draws again primarily from national censuses and population registers, supplemented with labor force surveys where necessary.

Significant efforts were made to standardize the data since the original sources contain significant variation due to differences in national data collection and dissemination policies (Arslan et al, 2015). Censuses survey the entire population or a representative sub-sample, as is the case with the micro-census of Germany, at a single point in time. ${ }^{7}$ For each OECD country, DIOC provides aggregate stocks by educational attainment and various age groups, gender, labor market status, and migration status. ${ }^{8}$ Using this information, we are able to distinguish the native-born from the foreign-born, the tertiary educated from the non-tertiary educated, and older from younger workers in each OECD country, and to determine the size of each labor group. Since the dataset is in a bilateral format, we can also construct the emigrant labor stocks of the OECD countries. We should emphasize that the bilateral nature of the DIOC (and DIOC-E) data is a very unique and valuable feature. Otherwise we could not obtain emigration numbers from the censuses of individual destination countries as they only give information on people who are present at the time, not of those who have left the country.

Table 1 presents age distribution by migration status across OECD countries and the age distribution of emigrants from these countries for the year 2010. The first set of columns refer to native-born individuals, followed by a set of columns pertaining to immigrants. Two key observations emerge from Table 1: (i) immigrants and emigrants are generally younger than natives; and (ii) the age distribution of immigrants and natives differ across all countries. We see that in countries such as Japan, Italy, Germany and Greece, the 65+ years old comprise over a quarter of the population above age 25 . In almost all countries, they account for no less than 15 percent of the population. In comparison, migrants are younger in most of these countries. A close inspection of Table 1 reveals that the shares of natives between the ages of 45 and 64 also exceed the

\footnotetext{
${ }^{7}$ Censuses often focus on the resident population, whether they are regular or irregular.

${ }^{8}$ The DIOC database allows identifying the origin $\times$ education $\times$ age dimension, or the origin $\times$ age $\times$ status dimension. For each country of destination, we extract the labor market status of young and old workers from the second and compute the old-to-young ratios of participation and employment rates. We then use these ratios to characterize the labor market status of workers by origin, education and age.
} 
corresponding shares among immigrants in almost all countries.

Information on labor market status allows us to distinguish between the stock of workers $\left(Q_{S A M}\right)$ and the employment levels $\left(q_{S A M}\right)$ of each type of worker. In order to empirically examine how demographic changes affect the relative wages of native workers across different age-education cells, we restrict our attention to individuals between the ages of 25 and 64 . The lower bound of 25 is chosen to reduce the incidence of having (i) foreign-born individuals who migrated for education purposes and (ii) natives who have not yet completed their education and entered the labor force.

Young and old workers both can be high-skilled or low-skilled in terms of education. The relative change between 2000 and 2010 in the stock of a given type of worker $(S A M)$ is computed as:

$$
\widehat{Q}_{S A M}=\frac{\Delta Q_{S A M}}{Q_{S A M}^{2000}} .
$$

More precisely, $\Delta Q_{S A M}$ is defined as $\Delta Q_{S A M}=Q_{S A M}^{2010}-Q_{S A M}^{2000}$.

The relative changes in the stocks of different worker groups are given in Table 2. Columns 1 to 4 show relative changes resulting from changes in the age-education structure of the native labor force, columns 5 to 8 show relative changes in the stock of immigrants in the country and columns 9 to 12 show relative changes resulting from natives emigrating or returning to their home country. A negative sign on values for emigration imply that there was a reduction in the stock of the native workforce due to increased rate of emigration between 2000 and 2010 .

Among natives, the stocks of old high-skilled workers exhibit the highest rates of relative increase. This is the case in almost all countries in our data, in particular, in European countries where the rate of increase is often higher. For example, the increase was 115 percent in Spain, 53 percent in Ireland, 65 percent in France and 83 percent in the UK. The exceptions are the Czech Republic, Denmark, Norway and Germany where we see an increase of 25 percent or less, arguably because the stock of old highskilled workers was already quite large in 2000. Other non-European OECD countries show similarly large changes. The USA, Canada and Australia have relative increases of over 40 percent. The stocks of older low-skilled labor force also exhibit noticeable rates of relative increase between 2000 and 2010, although the magnitudes are generally much lower in comparison to the older high-skilled groups. Japan is an exception with a relative rate of decline of 18 percent. In short, all OECD countries saw an increase in the old age group in their native-born labor force, with a significantly larger increase among the higher-skilled older people.

In line with our discussion in the introduction we also see an increase in the share of young high-skilled workers in the labor force in most countries between 2000 and 2010 . The stocks of younger low-skilled workers, in contrast, show declines, except in the Czech 
Republic, the Slovak Republic and Turkey. This, in combination with the fact that the stocks of old high-skilled in the labor force significantly increased in all countries, suggests an overall shift toward a more educated and older labor force in 2010 relative to 2000 . This shift is the main defining feature of the OECD labor markets that dominate our results.

Columns 5 to 8 of Table 2 point to a general increase in the stock of immigrants, both in the overall population and across age-education groups (with the exception of Poland, the Czech Republic and the Slovak Republic). However, the relative changes in stocks are not uniform across age-education groups as they mostly appear to be much higher among the high-skilled. Furthermore, it is unclear whether the increase among the older high-skilled dominates the increase among the younger high-skilled groups.

Emigration patterns show similar characteristics as those observed for immigration. The relative changes among the high-skilled dominate and patterns of return migration are visible among the low-skilled. New Zealand, Ireland, Poland and the Slovak Republic particularly stand out as emigration countries. While the first two countries are well known as migrant-sending countries, for the last two countries this is related to their joining the EU in 2004 and their citizens obtaining immediate freedom to work and live in Ireland, Sweden and the UK from then onward. In comparison to changes arising from socio-demographic changes, the relative changes due to emigration, although generally in the opposite direction, are quite small.

\subsection{Key parameters}

Common elasticities. - Simulation of the equilibrium wage effects of ageing, educational changes and migration requires the following key elasticity parameters. The analytical model includes a detailed discussion on their respectiive roles.

1. Elasticity of substitution between high-skilled and low-skilled workers $\left(\sigma_{S}\right)$. Most studies estimating the elasticity of substitution between high-skilled and low-skilled workers find a value no greater than 2. While Katz and Murphy (1992), Murphy et al. (1998) and Caselli and Coleman (2006) estimate $\sigma_{S}$ to be between 1.3 and 1.4, Fallon and Layard (1975), Angrist (1995) and Ciccone and Peri (2005) find values between 1.5 and 1.75, and Ottaviano and Peri (2012) find a value of about $2 .{ }^{9}$ We set $\sigma_{S}$ to 1.75 in our main scenario, the value DOP use in their intermediate scenario. We later examine how our simulated effects change when we allow $\sigma_{S}$ to take the value of 2, close to the value in Ottaviano and Peri (2012).

2. Elasticity of substitution between the old and the young workers $\left(\sigma_{A}\right)$. In one of the

\footnotetext{
${ }^{9} \mathrm{An}$ exception is Fitzenberger et al. (2006), who find values between 4.9 and 6.9, although they acknowledge this range is much higher than that found in prior studies.
} 
first studies to estimate this parameter, Katz and Murphy (1992) find a value of around 3. Card and Lemieux (2001), arguably one of the most influential papers on the extent of substitutability between young and old workers, estimate $\sigma_{A}$ across three countries. Using data on the US, Canada and the UK, they find values between 4 and 6. In more recent studies, Manacorda et al. (2012) estimate a value of around 5 using UK data, Ottaviano and Peri (2012) find a similar value using US data and, Glitz and Wissmann (2016) estimate values greater than 7 using German data. We set $\sigma_{A}=5$ in our main scenario, which is in the mid-range of these available estimates. Compared with our central estimate of $\sigma_{S}$, this assumption implies that workers in different age groups within the same skill group are more substitutable than workers in different skill groups, although still imperfectly so. We later allow for different values of $\sigma_{A}$ in order to explore the sensitivity of our simulated labor market effects to the degree of substitutability between age groups.

3. Elasticity of substitution between natives and migrants $\left(\sigma_{M}\right)$. The elasticity of substitution between migrants and natives, $\sigma_{M}$, is a crucial parameter in determining the effect of immigration on the labor market outcomes of natives. As such, this parameter has received a fair share of attention in the literature. On one hand, Borjas (2003) suggests perfect substitutability between immigrants and natives, implying a value of $\sigma_{M}$ equal to infinity. Card (2009), Ottaviano and Peri (2012) and Manacorda et al. (2012) find values of $\sigma_{M}$ between 6 and 20. In our empirical analysis, we set $\sigma_{M}$ to 20 , the value DOP use in their intermediate scenario. We again examine the implications of perfect substitutability on labor market outcomes in the extensions section.

4. Elasticity of labor supply $(\gamma)$. $\gamma$ captures how labor supply responds to changes in wages. In their synthesis of the literature, Evers et al. (2008) summarize estimates of $\gamma$ from various studies. Their meta-analysis suggests that 0.1 is a reasonable measure of this parameter among men and 0.5 among women. When simulating our labor market effects of interest, we use a conservative value of 0.1 in our baseline scenario.

5. Technological externalities $(\epsilon, \kappa)$. In the main analysis, we disregard technological changes and assume $\epsilon=\kappa=0$. In the long-run version of the model, $\epsilon$ measures the extent of productivity spillovers from having a higher share of highly skilled workers in the economy, as defined in equation (19). Acemoglu and Angrist (2000) and Moretti (2004) put $\epsilon$ at 0 and 0.75 , respectively. We assume an intermediate value of 0.30 in the extension. As for the skill-biased technical change, Acemoglu (2002) hypothesizes that the skill-biased technical change fully offsets the substitution effect in the long-run (i.e., $\kappa=1 / \sigma_{S}$ ). We consider both Acemoglu's (2002) hypothesis as 
well as a less extreme scenario where the skill-biased technical change offsets only half of the substitution effect (i.e., $\kappa=1 / 2 \sigma_{S}$ ). In the former case, technical change fully reverses the substitution effect in Eq. (15). In the latter case where $\kappa=1 / 2 \sigma_{S}$, Eq. (15) becomes $\frac{w_{H}}{w_{L}}=\Gamma_{0}\left(\frac{q_{H}}{q_{L}}\right)^{\kappa-1 / \sigma_{S}}=\Gamma_{0}\left(\frac{q_{H}}{q_{L}}\right)^{-1 / 2 \sigma_{S}}$.

Table 3 below summarizes values of the parameters we use in the main simulation.

Wage proxies. - We use the wage of a low-skilled young native worker (i.e., $w_{L Y N}$ ) as a reference wage, and use proxies for the skill, age and immigrant premia to compute the wage rates of other workers. We use skill premium data from Hendricks (2004) for each country. Average immigrant wage premium for each country is taken from DOP, where they use figures from a number of papers published between 1993 and 2005. We compute age premium ourselves from the American Community Survey data and use this for all countries in our sample. The following are used to calculate the average wages of workers in the other seven groups:

- $w_{L O N}=(\mathrm{US}$ age premium $) \times w_{L Y N}$

- $w_{H Y N}=($ skill premium $) \times w_{L Y N}$

- $w_{H O N}=($ US age premium $) \times($ skill premium $) \times w_{L Y N}$

- $w_{L Y F}=($ immigrant premium $) \times w_{L Y N}$

- $w_{L O F}=($ immigrant premium $) \times($ US age premium $) \times w_{L Y N}$

- $w_{H Y F}=($ immigrant premium $) \times($ skill premium $) \times w_{L Y N}$

- $w_{H O F}=($ immigrant premium $) \times($ US age premium $) \times($ skill premium $) \times w_{L Y N}$

Productivity and preference parameters. When employment levels $\left(q_{S A M}\right)$ and wage rates $\left(w_{S A M}\right)$ are determined, we sequentially use Eqs. (13), (14) and (15) to calibrate the relative productivity parameters. First, we insert wage and employment data into Eq. (13) and calibrate $\left(\Gamma_{H Y M}, \Gamma_{H O M}, \Gamma_{L Y M}, \Gamma_{L O M}\right)$. This allows computing the composite $q_{S A}$ using Eq. (6). Second, we compute average wage for each $S A$ group as $w_{S A}=$ $\frac{w_{S A N} q_{S A N}+w_{S A F} q_{S A F}}{q_{S A N}+q_{S A F}}$, and substitute these wage rates into Eq. (14) to calibrate $\left(\Gamma_{H A}, \Gamma_{L A}\right)$. This allows computing $q_{S}$ using Eq. (5). Third, we compute the average wage rate by skill group as $w_{S}=\frac{w_{S Y} q_{S Y}+w_{S O} q_{S O}}{q_{S Y}+q_{S O}}$, and plug them into Eq. (15) to calibrate $\Gamma_{S}$. This allows computing $q$ using Eq. (4), and calibrate the TFP to match the GDP data using Eq. (3). We know that a fraction $1-\alpha$ of GDP serves to remunerate labor. Using $1-\alpha=2 / 3$, we calibrate the level of our reference wage, $w_{L Y N}$, to match the national wage bill.

As for preference parameters, we calibrate $\phi_{S A M}$ as a residual from Eq. (11). This gives $\phi_{S A M}=w_{S A M}^{-\gamma}\left(q_{S A M} / Q_{S A M}\right)$. In the extension with involuntary unemployment, we use 
data on unemployment stock data $\left(u_{S A M}\right)$ from DIOC in conjunction with the unemployment rates from the OECD Short-Term Labour Market Statistics, and the replacement rate of the national unemployment insurance scheme $(\beta)$ from the OECD fiscal database. This allows computing $\varpi_{S A M}$, the average income per active hour, and recalibrating $\phi_{S A M}$ as $\varpi_{S A M}^{-\gamma}\left(q_{S A M} / Q_{S A M}\right)$.

Validation of the calibration strategy. A key variable required in the analysis of the equilibrium outcomes is the share of total labor wage bill going to each type of worker in the labor force. These wage bill shares are generally computed by (1) using individual wages and total labor stocks from detailed labor force surveys; (2) using individual hours worked and total labor stocks from detailed labor force surveys; or (3) using total labor stocks and normalized wages, with one group of workers as the base group. Card and Lemieux (2001) and Manacorda et al (2012) present an application of these different approaches. The desired labor force surveys are not publicly available in such microformat for most countrries; the available harmonised surveys for EU countries provide wage brackets, not the exact wages of individuals.

As a validation exercise, we thus compare our simulated wage bill shares with existing estimates available for 13 countries in the year $2010 .{ }^{10}$ The share of total wage bill going to a particular age group is the product of the size of that group and the normalized wage going to a given individual in that group, divided by the total wage bill of the entire economy. Results are depicted in Figure 4. The regression of observed wage bills on simulated shares shows a slope of 1.026 and an intercept of 0.003 (R-squared of 0.918), which is almost identical to the $45^{\circ}$ line. This shows that the imputation strategy used to construct wage rate proxies (which involves a constant age premium for all countries, and a country-specific immigrant premium for all skill-experience cells) is very consistent with labor force survey data.

\section{Equilibrium wage effects}

In this section, we use the benchmark labor market model to quantify the relative and aggregate wage effects of the socio-demographic changes (education and ageing) and migration that have taken place between 2000 and 2010, for non-migrant natives by skill and age group. Remember the model is calibrated to match the wage structure observed in the year 2010. We simulate counterfactual wage structures in 2010 as if socio-demographic changes had not happened, and express the wage effect as a percentage of the counterfactual level. In other words, the wage effects are computed as $\left(w_{S A M}-w_{S A M}^{c f}\right) / w_{S A M}^{c f}$, where $w_{S A M}^{c f}$ is the equilibrium wage rate obtained in the counterfactual without ageing,

\footnotetext{
${ }^{10}$ This group includes Austria, Belgium, Switzerland, Spain, Ireland, Hungary, Greece, the United Kingdom, Italy, Norway, Poland, Portugal and the United States.
} 
education or migration. This relative deviation captures the wage response to each sociodemographic force. We first describe the joint effect of education and ageing. We then discuss the effects of immigration and emigration. We finally compute the total effects and identify the main source of variation.

\subsection{Ageing and education composition}

The wage effects on non-migrant natives due to changes in the socio-demographic (ageeducation) structure of the native labor force are reported in Figure 5. Table of results for individual countries are also reported in Appendix D (Table A.2) for clarity of exposition. The ordering of the countries starts with Anglo-Saxon countries, followed by continental European countries, Scandinavian countries, Eastern and Central European countries and ends with Japan and Turkey. The wage effects are illustrated with thesolid diamonds for the older high-skilled workers, the solid circles for the younger high-skilled, the hollow diamonds for the older low-skilled, and with the hollow circles for the younger low-skilled workers.

Several clear patterns emerge from Figure 5. First, differences across skill groups exceed differences across age groups, implying that changes in the education composition of the labor force is the dominant factor. In most countries, older high-skilled workers are the most negatively impacted by the changes in the age-education structure of the labor force. They are followed closely by younger high-skilled workers. In Eastern European countries that recently joined the OECD, such as Poland and Hungary, the impact on the young high-skilled is actually more acute. Second, younger low-skilled workers are the largest beneficiaries of changes in the age-education structure of the labor force in almost every country, this time, followed closely by older low-skilled workers. These results are not particularly surprising in light of the patterns observed in Table 2, which depicted a relative increase in the stocks of older high-skilled workers and a decline in the stocks of younger low-skilled workers between 2000 and 2010. Older high-skilled workers face increased competition from both rapid ageing and educational upgrading in the labor forces of many countries while younger low-skilled workers have the exact opposite experience. However, as the figure clearly shows, the impact of educational composition improvement is more pronounced with both high-skilled groups experiencing negative effects.

The negative wage effects on the older high-skilled people are more pronounced in continental European countries, with the magnitude of the effect being as high as 20 percent in some countries (e.g. Italy and Spain). In a traditional old-age country such as Japan, the magnitude of the effect of ageing is smaller (13 percent), arguably because the base stock of older workers was already large in 2000. In English-speaking AngloSaxon countries the effects range from negative three percent in New Zealand to eight 
percent in the United States, ten percent in Canada and Australia and 18 percent in the United Kingdom. In line with the changes in the age-education structures presented in Table 2, the magnitude of the negative effects are about 16 percent in Eastern European countries such as Hungary, Poland and Turkey, i.e. those that are in the final stages of their demographic transition.

The wage effects on younger high-skilled workers are almost negative throughout all countries, with the lone exception of New Zealand (+2.2 percent). These effects are similar to the effects on older high-skilled workers, especially in relatively higher-income countries. The median effect is -10 percent for the wages of the younger high-skilled workers as opposed to -14 percent for the old workers. Similarly, the median wage effect is +4 percent for older and +8 percent for the younger low-skilled workers. The clear wage gains for younger low-skilled workers are visibly clear as the orange line is consistently above all other lines and is positive in Figure 5. Although there are increases in the relative stocks of older low-skilled workers between 2000 and 2010 in most countries, the magnitudes of these changes are much smaller in comparison to the changes in the number of the older highly skilled workers. Additionally, this former group benefits from the productivity spillovers generated from having significantly more high-skilled workers, regardless of their age distribution. We also see from the equilibrium solution in Section 2.4 that there is a positive relationship between the wages of the low-skilled and changes in the quantity of the high-skilled workers, even in the absence of a productivity spillover. These factors counteract the negative wage effects that would have resulted solely from relative increases in their (own-type) stocks. Therefore, similar to their younger counterparts, older lowskilled workers experience wage gains, though in smaller magnitudes.

In conclusion, it is evident that the low-skilled and the younger workers are the main beneficiaries in terms of wages. The high-skilled are clear losers and the average effects vary across countries for older workers. The latter is also driven by the fact that older low-skilled workers account for a larger proportion of the labor force in the base year and so do their wage bills. Therefore, a small positive gain for them may outweigh large losses for the high-skilled when computing average wage effects across age groups.

A natural question to ask is how the wage effects are split between "ageing" and "educational change" components. As Figure 5 indicates, the education effect is the dominant one. The wage gap between the younger and older workers of the same skill category are much smaller than the reverse. In Appendix C, we describe the details of the decomposition exercise which shows this pattern more clearly for each labor group.

The education effect appears as the larger one from this decomposition. The left panel of Figure 6 presents the wage effects of the changes in the education composition across different labor groups in each country. The right panel presents the wage changes due to ageing. In addition to being smaller in magnitude, impact of ageing is more uniform across 
countries and labor groups, possibly due to its smoother transition over time relative to the more rapid and sporadic pace of changes in education composition. When we look at the wage effects of education change, the positive impacts on the young and old low-skilled workers are quite close to each other in almost every country. The same is also true for the negative effects on the high-skilled groups. With the exception of New Zealand where the effects are negligible, the impact on the high-skilled groups ranges between negative 5 and 25 percent. Eastern European countries, such as Poland and the Slovak Republic, which are now rapidly ageing, seem to be suffering the most.

The wage effects of ageing across labor groups are not surprising either.The young workers, represented with circles on the right panel of Figure 6, benefit whether they are low or high skilled. Similarly, older workers, diamonds, are hurt. The range of the impact, however, is much smaller when compared to education. For example, the wage gains for the younge workers are never above 4 percent. Older workers, in parallel, never experience losses larger than 5 percent. In short, the wage impact is dominated by the changes in the education composition (an increase of high-skilled workers), rather than the age composition (an increase of older workers) in most countries. This is partly due to higher substitutability between older and younger workers (as opposed to between low and high skilled) and partly due to differences in the pace of change of education and age composition.

\subsection{Immigration}

The effects on the wages of natives due to changes in the stock of immigrants are reported in Figure 7 and in Appendix D (Table A.3). The ordering of the countries remains the same and the shapes illustrating the wage effects are of the same colors as those depicting the wage effects of socio-demographic composition change in Figure 5. In many countries, the increase in the stock of immigrants (as observed in Table 2) has negative wage effects for the highly skilled natives regardless whether they are old or young. There are several exceptions in Western Europe, such as Belgium, the Netherlands, Italy, Spain, Greece, Finland and Denmark, but the positive effects are small in many of these cases.

Immigration has generally positive effects on the low-skilled workers regardless of their age group, especially in countries that manage to attract a higher share of skilled migrants, such as Canada, Australia, New Zealand and Switzerland. There are exceptions to this pattern as well, mostly with countries in Western Europe. The few cases of negative effects are small in magnitude and are slightly below zero. In key immigrant destination countries such as Canada, Australia, New Zealand, the UK and Switzerland that attract high-skilled migrants, the gains for the low-skilled natives (hollow circles and diamonds) tend to be significantly higher. The wage gain, for example, is 5 percent in Australia, Canada, and Switzerland and 3 percent in the UK and New Zealand. These findings are 
consistent with the results in DOP on the impact of the immigration flows of the previous decade between 1990 and 2000. More importantly, the results exhibit a certain degree of contradiction to the popular perception that immigration has large negative effects on the wages of low-skilled native workers in all destination countries. On the contrary, both old and young low-skilled workers experience wage gains and are the main beneficiaries of relatively high-skilled immigration in a number of destination countries, such as Australia, Canada and Switzerland.

Our model and calibration allow for differential wage effects of immigration on native workers across different age groups. This is different than the set-up in DOP where there are no age group distinctions in the labor market modelling. Nevertheless, the results show that wage gains and losses are relatively symmetric across age groups within the same skill category in the vast majority of the OECD destination countries. There are some small differences for example, such as in Italy and Spain, suggesting that the (implicit) assumption of symmetric effects in DOP may not necessarily hold.

Our analysis is based on the net changes in immigrant stocks presented in Table 2. The DIOC database provides information in 2010 on the duration of stay of immigrant groups by education category. More specifically, we have data on the education composition of the migrants who arrived between 2000 and 2010. In Appendix A, we discuss in detail how we use these data to calculate the wage impact of this gross inflow, rather than the net change. In most countries, the results are almost identical (see Figure A.1) since there is high degree of correlation between the gross inflow and net change in immigrant stocks

\subsection{Emigration}

The wage effects due to emigration show different patterns when compared to those that result from changes in immigrant stocks. The low-skilled non-migrant natives now suffer wage losses, especially in higher-income countries, and, in contrast, the high-skilled are the beneficiaries. These patterns are illustrated in Figure 8 and in Appendix D (Table A.4). The heterogeneity in wage effects from emigration is also clear. Countries which experienced low levels of relative changes in the age-education structure of natives due to emigration (such as those in Scandinavia or Eastern Europe) experience almost no wage effects for all groups. These differences are simply due to the high-skill intensity of emigration flows. The positive correlation between the impact on the wages of the low-skilled and changes in quantities of high-skilled labor means wage losses among the low-skilled are more pronounced in high-skilled emigrant sending countries like Ireland and Eastern European countries. The impact is especially pronounced in Ireland where older low-skilled workers suffer a wage loss of 5 percent, along with losses for their younger counterparts. In the other countries, the losses of the older and younger lower-skilled workers are smaller. Because the low-skilled workers account for a larger share of the 
total wage bill and the wage losses they experience dominate the wage gains of the highskilled, emigration ends up having negative average wage effects on the labor force.

\subsection{Total effect}

The total wage impact of changes in the age and education composition, immigration and emigration levels is depicted in the four panels of Figure 9 and in Appendix D (Table A.5). The ordering of the countries is the same as before and each one of the panels presents the results for the labor group identified in its respective title. The diamonds present the impact of socio-demographic (age-education) changes, solid circles are for immigration, empty circles are for emigration, and the empty squares are for the total effects.

The most striking observation is the general dominance of the impact due to sociodemographic changes (age and education) relative to the effects from the changes in immigrant and emigrant stocks. That is why the "squares" are so close to the "diamonds" in each panel. Furthermore, in almost all countries, we observe positive (combined) wage effects for the low-skilled and lower wages for the highly skilled regardless of their age groups. New Zealand is an exception. In contrast, the total combined effect reaches around negative 20 percent for the higher skilled in several countries (such as Portugal). The average total wage impact is negative 13 percent for the older high-skilled workers and negative 10 percent for the younger high-skilled. In contrast, the combined effect is 9 percent for the young low skilled and 5 percent for the old low-skilled.

\section{Extensions}

In this section, we assess the robustness of our results to the choice of elasticities and to the specification of the labor market model as discussed in sections 2.5 to 2.7 above.

\subsection{Changes in elasticities}

We examine various extensions in this section where we change the values of the key parameters of the model from their original values used in the main scenario discussed above. We start by changing one parameter at a time and the median wage effects resulting from these changes are presented in Table 4, with the minimum and maximum values in brackets. The first panel of the table repeats the baseline results for ease of comparison.

The first scenario, presented in the second panel, allows for a much higher degree of substitutability between skill groups in the production function by setting $\sigma_{s}=2$. With the new elasticity level, the wage effects due to socio-demographic, immigration and emigration change. In comparison to the main scenario, the resulting wage losses 
from socio-demographic composition changes are relatively smaller for the high-skilled workers. To put it differently, as they become better substitutes for low-skilled workers, the larger number of high-skilled workers now experience smaller losses to their relative wages. In the same vein, the low-skilled workers, both young and old, experience smaller wages gains. Similarly, immigration has (marginally) reduced negative effect on the wages of the high-skilled and on the gains to the low-skilled. These results are again due to the fact that the relatively higher share of the high-skilled workers among the immigrants is now less damaging to the high-skilled natives and less advantageous for their low-skilled counterparts. Changes in the wage effects from emigration are governed by identical mechanisms. When we look at the total effect, changes in age-education composition contribute almost all of it with emigration and immigration canceling each other out.

In the second scenario, presented in the third panel of Table 4, we increase the degree of substitutability between age groups by setting $\sigma_{a}=7$. In comparison to the baseline scenario, the young low-skilled workers experience a decline in their wage gains. The substitutability between them and older low-skilled workers increases, which in turn, dampens the gains from large reduction in their stocks. Similarly, the gains for the older low-skilled increases. We see a parallel result for the high-skilled workers. The younger high-skilled workers now lose even more while the losses of the older high-skilled are pared down. Finally, the new scenario leads to little change in the wage effects arising from immigration or emigration, in comparison to the main scenario.

The third scenario makes the immigrants almost perfectly substitutable with natives by setting $\sigma_{m}=1000$. This magnifies the negative wage effects of immigration on the highskilled workers, but the wage gains to the low-skilled remain fairly stable. The elasticity parameter we have changed has little importance in the slope of the wage responses to changes in the quantity of the native labor force, and the resulting wage effects from ageing and emigration are negligible.

\subsection{Involuntary unemployment with redistributive benefits}

Our next extension changes certain assumptions we made about labor markets and unemployment as discussed in section 2.5. Recall that we first introduce involuntary unemployment into the model where we assume workers face exogenous job separation and matching rates. As a result workers spend a certain fraction of their time in unemployment as they search for a new match. The unemployment rates are assumed to be group-specific and we obtain these data from DIOC and the OECD short-term labour market statistics. Next, we introduce unemployment benefits that are equal to a fraction $\beta<1$ of the average wage rate of the economy. We assume all workers receive the same benefits which makes the insurance program redistributive. Insurance leads to the modification of the labor supply function where the average wage incorporates the insurance payment weighted by 
the probability of unemployment.

When we calibrate the model with this new labor supply function and plot the new wage effects against the baseline results, we obtain the pattern presented in Figure 10. The baseline aggregate results, combining the effects of demograhic and education changes as well as migration, are plotted on the $\mathrm{x}$-axis and the new labor market scenario is plotted on the y-axis. We have almost identical results for the high-skilled groups (who experience wage losses) and high level of correlation for the low-skilled groups (who experience gains). These results indicate that the presence of unemployment insurance does not really change the overall results.

The main exceptions to the correlation between the baseline and the modified scenarios are found in two groups of countries. In the first group of countries with high low-skilled unemployment rates due to the financial crisis, such as Spain and Portugal, the low skilled workers experience wage gains around 10 percent. With unemployment insurance these gains are now much less. In the second group of countries with very generous unemployment benefits, such as Switzerland and Luxembourg, again we find large differences between the baseline and the new scenario. These patterns are due to the fact that labor participation responses are attenuated when redistributive unemployment benefits are large. This is particularly the case in countries where unemployment is high (Spain and Portugal) and wage replacement rates are generous (Switzerland and Luxembourg). Hence, the income gains experienced by low-skilled workers become smaller as a result when redistributive benefits are included.

\subsection{Capital mobility}

One of the critical assumptions and the source of many debates is on how capital mobility is introduced into these models. In the baseline scenario, we assumed capital is mobile and, hence, the return to capital is fixed and identical in all of the countries. As a result, output becomes a linear function of the labor composite and the wage bill equals a fixed share of the national output. When we assume capital stock is not mobile or is fixed, these assumptions no longer hold. As the capital stock available per worker declines with increase in composite labor stock, the new equilibrium wage rate needs to incorporate this labor stock change. More specifically, wage rates for all labor groups are multiplied by a factor given by $(\bar{k} / q)^{\alpha}$ where $\bar{k}$ is the fixed capital stock and $q$ is the composite labor stock. In other words, as discussed in section 2.6, if composite labor stock increases from $q$ to $q^{\prime}$, all of the new wage rates are now multiplied by $\left(q^{\prime} / q\right)^{-\alpha}$.

The combined wage effects under fixed capital stocks are presented in the y-axis of Figure 11 where the baseline results are again in the x-axis. Almost all the points are below the 45-degree line. In the presence of fixed capital, wages in most countries are now lower when compared to the baseline case of perfectly mobile capital. Since $q^{\prime}$ exceeds 
$q$ in almost all countries, the fixed-capital simulation shifts the effects downward, but it does not change the inequality effects. The few exceptions above the diagonal line are for those countries that are actually experiencing declines in their composite labor forces and, therefore, increases in per-worker capital stocks.

\subsection{Technological changes}

Our final extension incorporates endogenous TFP and directed technical change assumptions. In a simple Lucas-style aggregate externality, TFP is a concave function of the skill ratio in the labor force with a constant elasticity. This assumption is based on innovative capabilities and productivity externalities generated by the higher-skilled workers in the economy. The second externality (i.e. directed technical change) captures the relative demand shift in favor of college-educated workers induced by the rise in the skill ratio.

As we discuss in section 2.6, we initially assume skill-biased technical change offsets half of the substitution effect between the high and low skilled workers (i.e. $\kappa=\frac{1}{2 \sigma_{S}}$ ). Figure 12 presents the new wage effects under these assumptions about longer term productivity changes. The left graph is for the high-skilled and right one is for the low-skilled workers. The baseline scenario results are again in the $\mathrm{x}$-axis and the new scenario is depicted on the $y$-axis. There is a clear pattern emerging with these new assumptions. When schooling externalities are factored in, the rise in educational attainment translates into higher TFP and higher demand for high-skilled workers. These two effects offset each other for low-skilled workers. The low-skilled workers' wage changes are almost identical in either scenario (i.e., close to the $45^{\circ}$ line), ranging between zero and 22 percent. Both the young and old low-skilled workers experience almost the same wage gains in the presence of significant productivity spillovers and technical change in the economy. In contrast, the experience of the high-skilled workers is quite different as both externalities reinforce each other in increasing their productivity. In the baseline scenario, college-educated workers faced wage losses in almost every country since there was a rapid increase in the relative share of the high-skilled in the labor force. The substitution effect was quite strong. Now, in the presence of spillovers and technical change, these wage losses are almost fully neutralized, and the high-skilled workers experience minimal wage losses or gains in some cases. The range of the effect is between negative and positive 5 percent. Hence, both directed and aggregate schooling externalities compensate for the (negative) substitution effects that would dominate the wage effects of the high-skilled workers.

As shown in Figure 13, these effects are magnified when assuming $\kappa=\frac{1}{\sigma_{S}}$. Skillbiased technical change fully offsets the substitution effect between the high and low skilled workers. In other words, the egalitarian effects of socio-demographic changes almost disappear. Now, the low skilled workers (right panel) still experience wage gains but the effect is smaller than the baseline scenario. The majority of the gains are between zero 
and 10 percent. The majority of the high-skilled workers also experience gains that lie within the same range. When the technical change fully compensates the substitution effect as Acemoglu (2002) states, the relative gain of the low-skilled workers we saw in the baseline scenario almost fully disappears. The positive and almost equal gains that both groups experience are now due to higher TFP resulting from higher human capital in the labor force.

\section{Conclusion}

While the effects of ageing, education and migration on wages have been studied before, no previous analysis has considered all three together. This integrated treatment helps us to assess the relative and aggregate force of these three developments. Our most striking conclusion is that changes in the age and skill structure of the population dwarf the effects of immigration and emigration in most countries. For the most part, these big demographic changes boost the wages of the low-skilled, on the one hand by making them relatively scarce and on the other hand by increasing their productivity - because the low-skilled can work with relatively more skilled people. Immigration, the villain in much political discourse, turns out to be a relatively feeble and actually positive phenomenon.

Whereas in most of Western Europe, Japan and the United States, ageing and changes in the stock of high-skilled workers account for most of the changes in wages, migration plays a more significant role in two groups of countries. In the Anglo-Saxon countries (Australia, Canada, New Zealand, the United Kingdom) and Switzerland, which have relatively liberal and skill-biased immigration policies, immigration reinforces the impact of ageing on wages since the immigrants tend to be more skilled on average than natives. In countries that have seen significant labor outflows, such as Ireland and certain Eastern European countries (the Czech Republic, the Slovak Republic, Hungary and Poland) the impact of ageing is partially offset by emigration, because emigrants too tend to be more skilled than natives. However, the impact of emigration never completely offsets the combined effect of the changing age-skill composition and immigration. Therefore, the aggregate effect of all these changes is egalitarian: for both young and old, the wages of the unskilled are higher and wages of the skilled are lower than they would have been if these changes had not happened.

We recognize that our findings emerge from a model that abstracts from other important changes that occurred during this decade, especially in technology. As we show, relaxing assumptions about the degree of substitutability between labor groups, capital mobility, and the possibility of unemployment does not fundamentally alter our results. However, allowing for sufficiently strong skill-biased technological change can offset the egalitarian effects of the increase in skill endowments, and help to reconcile the narrowing 
of wage gaps predicted by our model with the observed skill premium in many countries. Nevertheless, abstracting from these other changes helps us to isolate and highlight the relative impact of the demographic forces that are shaping the wage-structure in industrial economies, both to inform the political debate and to identify reform priorities. 


\section{References}

[1] Acemoglu, D., \& Angrist, J. (2000). How large are human-capital externalities? Evidence from compulsory schooling laws. in B. S. Bernanke and K. Rogoff (editors). NBER Macroeconomics Annual, 15, 9-59.

[2] Acemoglu, D. (2002). Technical change, inequality, and the labor market. Journal of Economic Literature, 40(1), 7-72.

[3] Amuedo-Dorantes, C., \& De la Rica, S. (2007). Labour market assimilation of recent immigrants in Spain. British Journal of Industrial Relations, 45(2), 257284

[4] Angrist, J. (1995). The economic returns to schooling in the West Bank and Gaza Strip. American Economic Review, vol. 85(5), pp. 1065-87.

[5] Arslan, C., Dumont, J.-C., Kone, Z., Moullan, Y., Özden, C., Parsons, C., \& Xenogiani, T. (2015). A new profile of migrants in the aftermath of the recent economic crisis. OECD Social, Employment and Migration Working Papers, (160).

[6] Autor, D. H., Levy, F., \& Murnane, R. J. (2003). The skill content of recent technological change: An empirical exploration. Quarterly Journal of Economics, 118(4), 1279-1333.

[7] Autor, D. H., Katz, L. F., \& Kearney, M. S. (2008). Trends in US wage inequality: Revising the revisionists. Review of Economics and Statistics, 90(2), 300-323.

[8] Battisti, M., Felbermayr, G., Peri, G., \& Poutvaara, P. (2018). Immigration, Search and Redistribution: A Quantitative Assessment of Native Welfare. Journal of the European Economic Association, 16(4), 1137-1188.

[9] Blake, D., \& Mayhew, L. (2006). On the sustainability of the UK state pension system in the light of population ageing and declining fertility. Economic Journal, 116(512), F286-F305.

[10] Bleakley, H., \& Chin, A. (2004). Language Skills and Earnings: Evidence from Childhood Immigrants. Review of Economics and Statistics, 86(2), 481-496.

[11] Bloom, D. E., Canning, D., \& Fink, G. (2010). Implications of population ageing for economic growth. Oxford Review of Economic Policy, 26(4), 583-612.

[12] Bound, J., \& Johnson, G. (1992). Changes in the structure of wages in the 1980's: an evaluation of alternative explanations. American Economic Review, 82(3), 371. 
[13] Borjas, G. J. (2003). The labor demand curve is downward sloping: Reexamining the impact of immigration on the labor market. Quarterly Journal of Economics, 118(4), $1335-1374$.

[14] Burzynski, M, Docquier, F., \& Rapoport, H. (2018). The changing structure of immigration to the OECD: what welfare effects on member states? IMF Economic Review, 66(3), 564-601.

[15] Card, D., \& DiNardo, J. E. (2002). Skill-biased technological change and rising wage inequality: Some problems and puzzles. Journal of labor economics, 20(4), 733-783.

[16] Card, D., \& Lemieux, T. (2001). Can falling supply explain the rising return to college for younger men? A cohort-based analysis. Quarterly Journal of Economics, 116(2), 705-746.

[17] Card, D. (2009). Immigration and Inequality. American Economic Review, 99(2), $1-21$.

[18] Caselli, F., \& Coleman, W. J. (2006). The world technology frontier. American Economic Review, 96(3), 499-522.

[19] Chassamboulli, A. \& Palivos, T. (2014). A search-equilibrium approach to the effects of immigration on labor market outcomes. International Economic Review, 55(1), 111-129.

[20] Chiswick, B. R. (1978). The effect of Americanization on the earnings of foreign-born men. Journal of political Economy, 86(5), 897-921.

[21] Ciccone, A., \& Peri, G. (2005). Long-run substitutability between more and less educated workers: evidence from US states, 1950-1990. Review of Economics and Statistics, 87(4), 652-663.

[22] Czaika, M., \& Haas, H. (2014). The globalization of migration: Has the world become more migratory? International Migration Review, 48(2), 283-323.

[23] Dustmann, C., Frattini, T., \& Preston I, P. (2013). The effect of immigration along the distribution of wages. Review of Economic Studies, 80(1),145173.

[24] Docquier, F., Ozden, Ç., \& Peri, G. (2014). The labour market effects of immigration and emigration in OECD countries. Economic Journal, 124(579), 1106-1145.

[25] Evers, M., De Mooij, R., \& Van Vuuren, D. (2008). The wage elasticity of labour supply: a synthesis of empirical estimates. De Economist, 156(1), 25-43. 
[26] Fallon, P. R., \& Layard, P. R. G. (1975). Capital-skill complementarity, income distribution, and output accounting. Journal of Political Economy, 83(2), 279-302.

[27] Fitzenberger, B., \& Kohn, K. (2006). Skill wage premia, employment, and cohort effects: are workers in Germany all of the same type?. University of Freiburg Working Paper.Freeman, R. (1976). The overeducated american. Academic Press, New York.

[28] Freeman, R. B. (1979). The Effect of Demographic Factors on Age-Earnings Profiles. Journal of Human Resources, 14(3), 289-318.

[29] Gagliardi, L., \& Lemos, S. (2016). Evidence on immigrants assimilation into recipient labour markets using UK longitudinal data between 1981 and 2006. Journal of Economic Geography, 16(3), 547583.

[30] Glitz, A., \& Wissmann, D. (2016). Skill Premiums and the Supply of Young Workers in Germany. Working Paper, Humboldt University Berlin.

[31] Goldin, C. and Katz, L. (2008). The Race Between Education and Technology, Cambridge, MA: Harvard University Press.

[32] Hendricks, L. (2004). A Database of Mincerian Earnings Regressions. Available at http://www.lhendricks.org/Mincer.htm.

[33] Katz, L. F., \& Murphy, K. M. (1992). Changes in relative wages, 1963-1987: supply and demand factors. Quarterly Journal of Economics, 107(1), 35-78.

[34] Lee, D. S. (1999). Wage inequality in the United States during the 1980s: Rising dispersion or falling minimum wage? Quarterly Journal of Economics, 114(3), 9771023.

[35] Lee, R. D. (2014). Macroeconomic consequences of population aging in the United States: Overview of a national academy report. American Economic Review, 104(5), 234-239.

[36] Leers, T., Meijdam, L., \& Verbon, H. A. (2004). Ageing, migration and endogenous public pensions. Journal of Public Economics, 88(1), 131-159.

[37] Lemieux, T. (2008). The changing nature of wage inequality. Journal of Population Economics, 21(1), 21-48.

[38] Lucas, R.E. (1988). On the Mechanics of Economic Development. Journal of Monetary Economics, 22, 342.

[39] Mahlberg, B., Freund, I., Cuaresma, J. C., \& Prskawetz, A. (2013). Ageing, productivity and wages in Austria. Labour Economics, 22, 5-15. 
[40] Manacorda, M., Manning, A., \& Wadsworth, J. (2012). The impact of immigration on the structure of wages: theory and evidence from Britain. Journal of the European Economic Association, 10(1), 120-151.

[41] Moretti, E. (2004). Workers' education, spillovers, and productivity: evidence from plant-level production functions. American Economic Review, 94(3), 656-690.

[42] Murphy, K. M., \& Welch, F. (1992). The structure of wages. Quarterly Journal of Economics, 107(1), 285-326.

[43] Murphy, K. M., Riddell, W. C., \& Romer, P. M. (1998). Wages, skills, and technology in the United States and Canada (No. w6638). National Bureau of Economic Research.

[44] Ottaviano, G. I., \& Peri, G. (2012). Rethinking the effect of immigration on wages. Journal of the European Economic Association, 10(1), 152-197.

[45] Ortega, F., \& Peri, G. (2014). Openness and income: The roles of trade and migration. Journal of International Economics, 92(2), 231-251.

[46] Patel, K., \& Vella, F. (2013). Immigrant networks and their implications for occupational choice and wages. Review of Economics and Statistics, 95(4), 1249-1277.

[47] Peri, G., \& Sparber, C. (2009). Task specialization, immigration, and wages. American Economic Journal: Applied Economics, 1(3), 135-169.

[48] Peri, G. (2012). The Effect Of Immigration On Productivity: Evidence From U.S. States. Review of Economics and Statistics, 94(1), 348-358.

[49] Restuccia, D. \& Vandenbroucke, G. (2013). The evolution of education: a macroeconomic analysis. International Economic Review, 54(3), 915-936.

[50] Sheiner, L. (2014). The Determinants of the Macroeconomic Implications of Aging. American Economic Review, 104(5), 218-223.

[51] United Natons (2013). International migration report 2013. United Nations Department of Economic and Social Affairs, Population Division, New York.

[52] World Bank. (2018). "Moving for Prosperity: Global Migration and Labor Markets," World Bank, Washington DC. 
Figure 1: Changes in population shares by age-education group (in percentage points), 20002010, natives

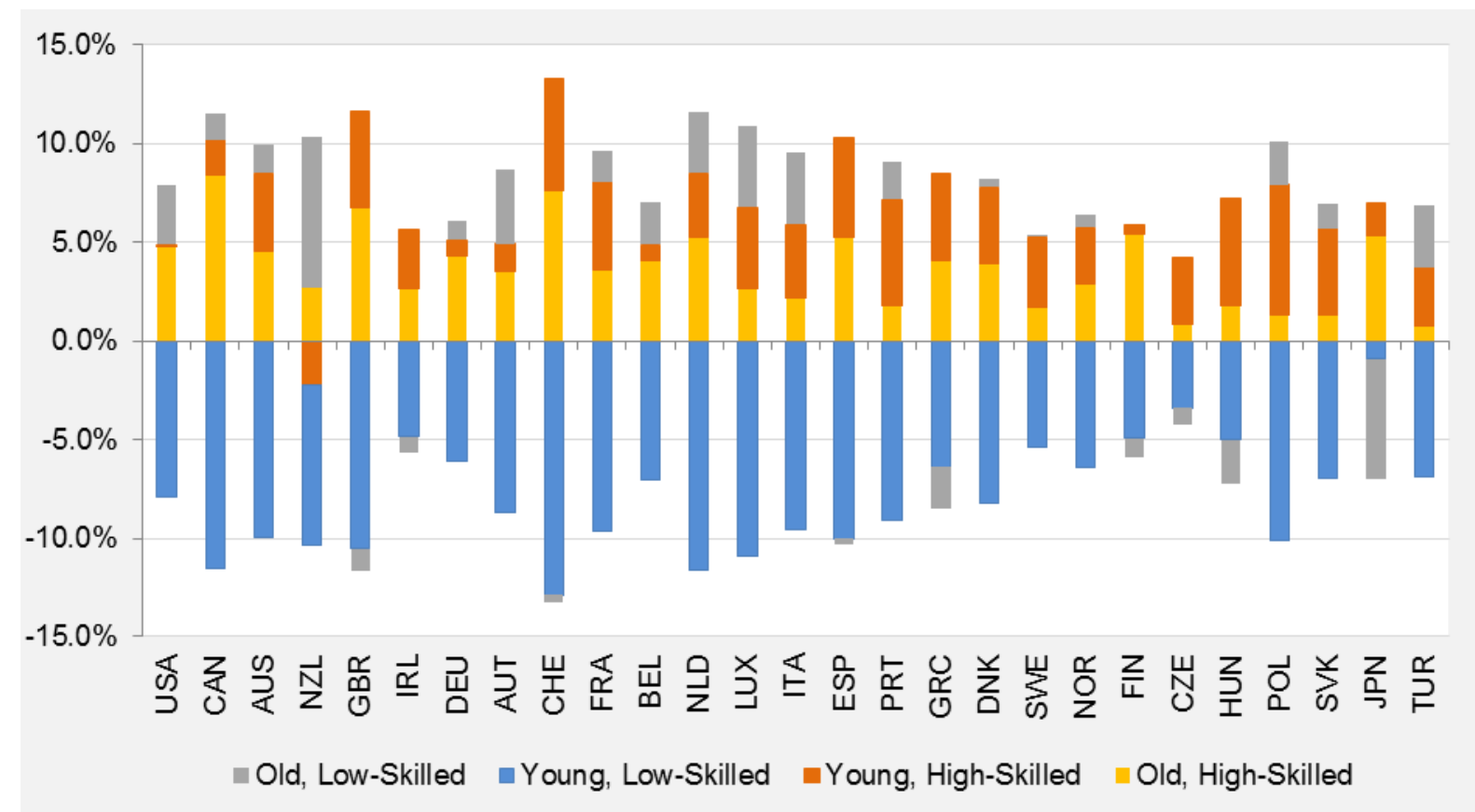

The figure illustrates changes in $\frac{Q_{S A}}{Q}$ amongst native-born between 2000 and 2010. Data cover to those of age 25-64. Young refers to those of age 25-44 and Old refers to those of age 45-64

Figure 2: Changes in population shares by age-education group (in percentage points), 20002010, immigrants

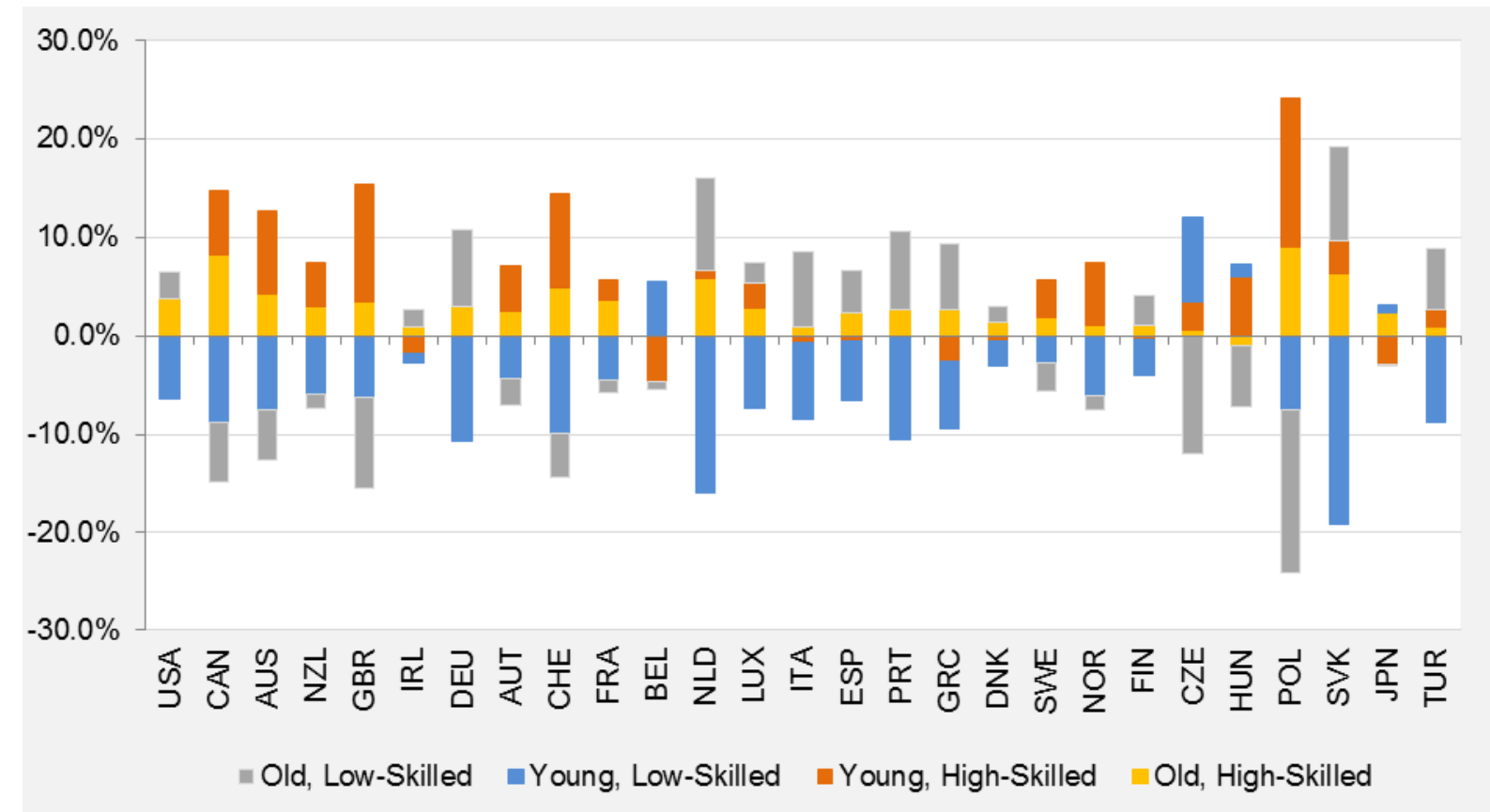

The figure illustrates changes in $\frac{Q_{S A}}{Q}$ amongst foreign-born between 2000 and 2010. Data cover to those of age 25-64. Young refers to those of age 25-44 and Old refers to those of age 45-64 
Figure 3: Nest structure of composite labor

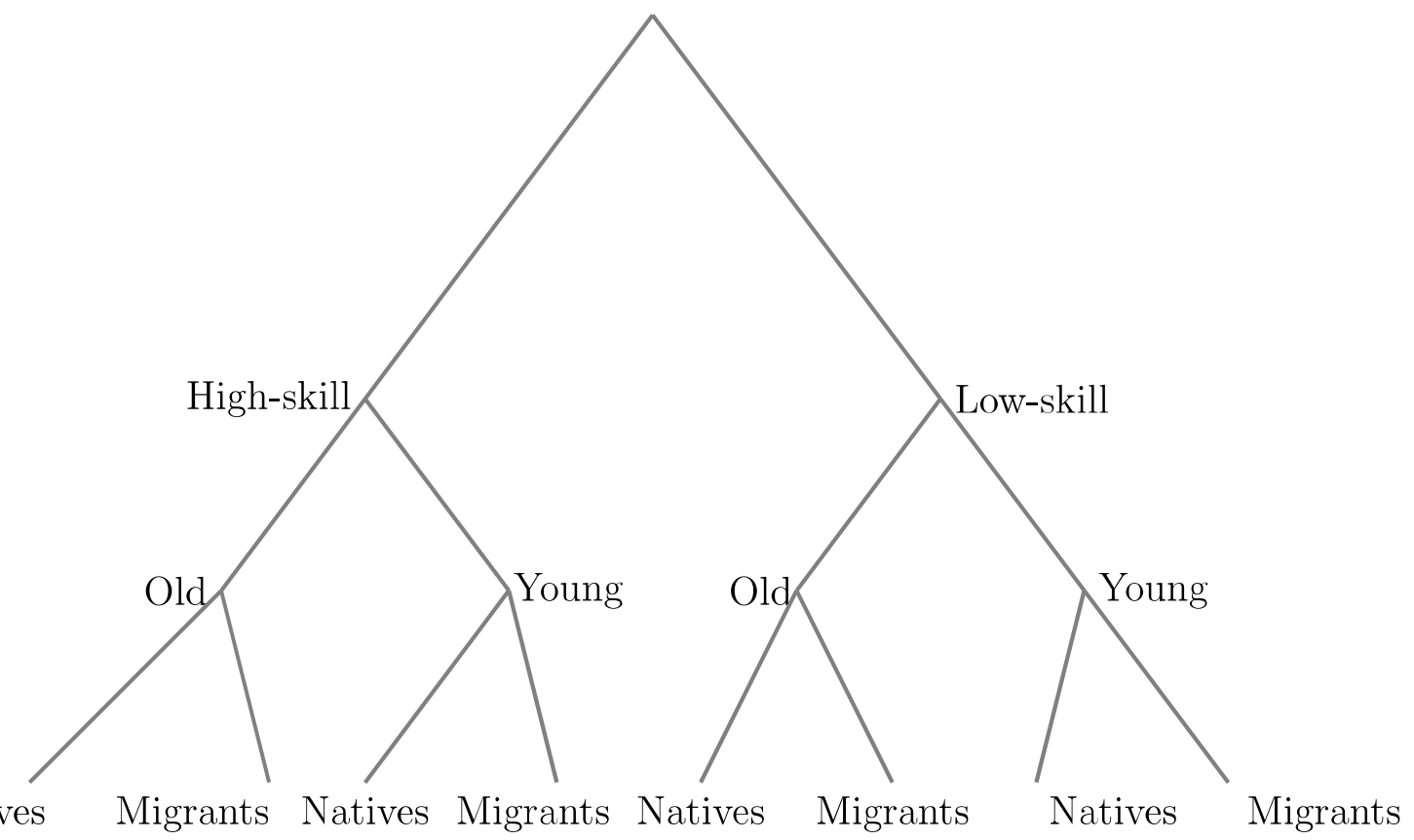

\section{Natives Migrants Natives Migrants Natives Migrants Natives Migrants}

Note: The figure illustrates the structure of the CES function described in the section where we present our analytical model

Figure 4: Observed vs. simulated wage bill shares, 2010

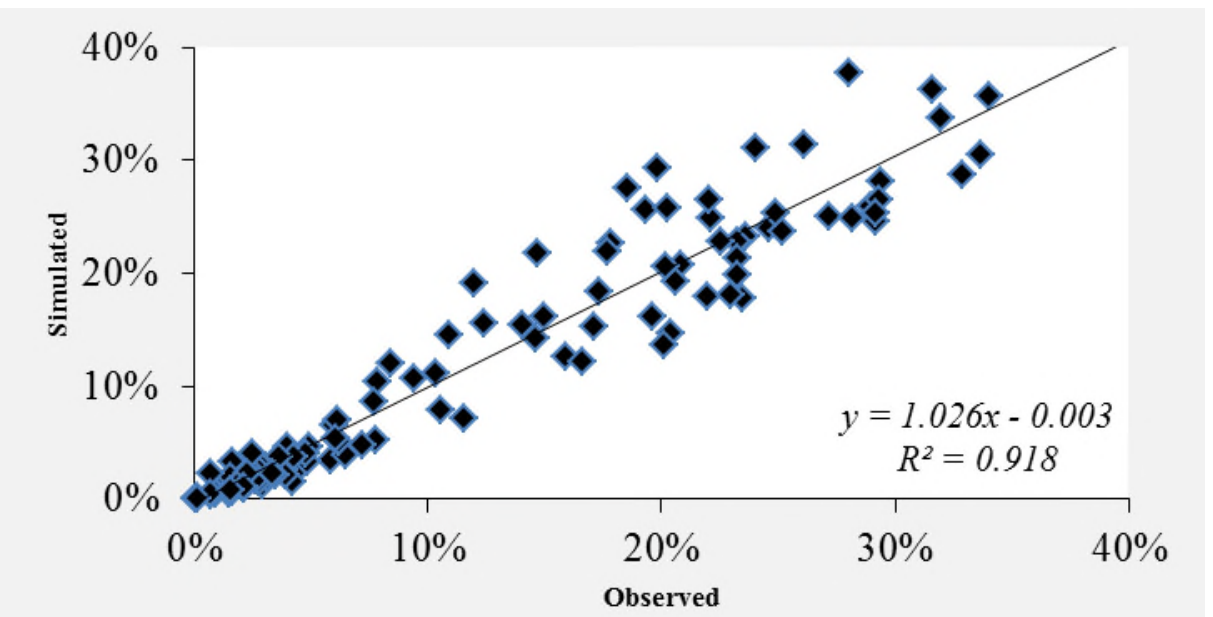

Note: The Y-axis denotes wage bill shares computed using information on earnings from the EU-SILC and the ACS. The $\mathrm{X}$-axis denotes wage bill shares computed as described in the data section 
Figure 5: Wage effects of socio-demographic changes, 2000 - 2010 (\%), by age-education group

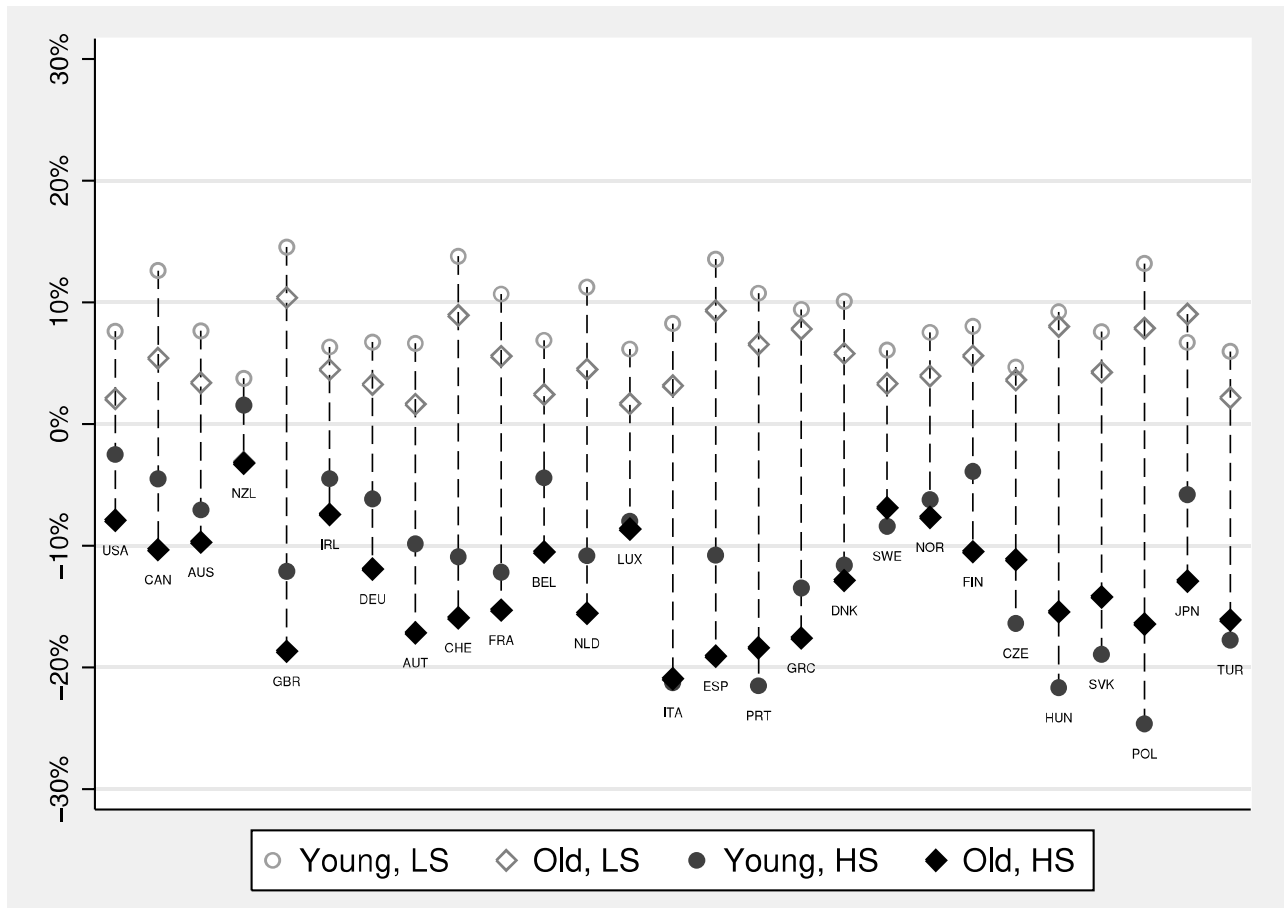

The figure plots equilibrium wage responses to changes in the age-education composition of natives

Figure 6: Decomposition of education and ageing effects

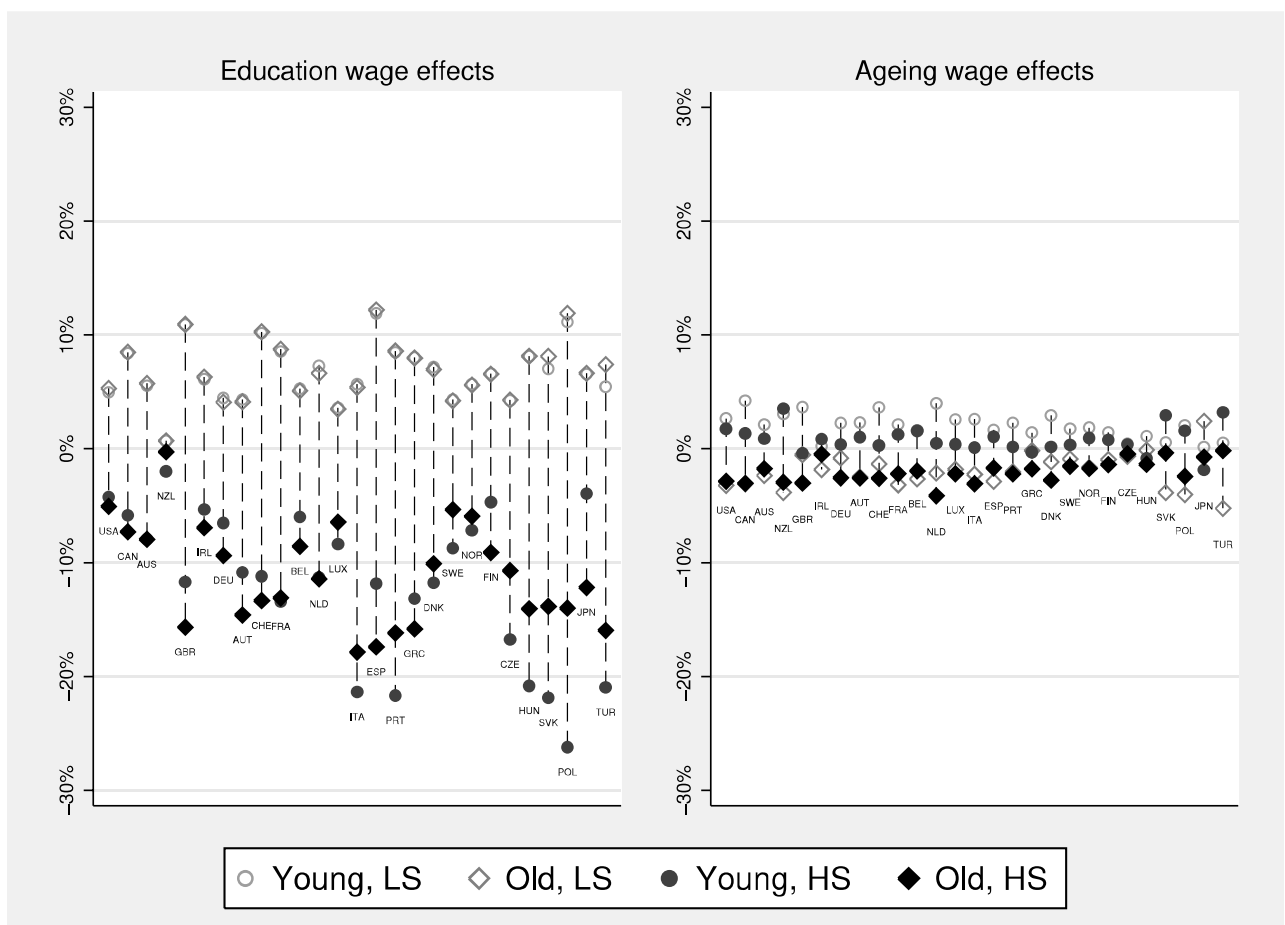

The figure splits the equilibrium responses presented in Figure 5 into changes due to ageing and those due to education 
Figure 7: Wage effects of immigration, 2000 - 2010 (\%), by age-education group

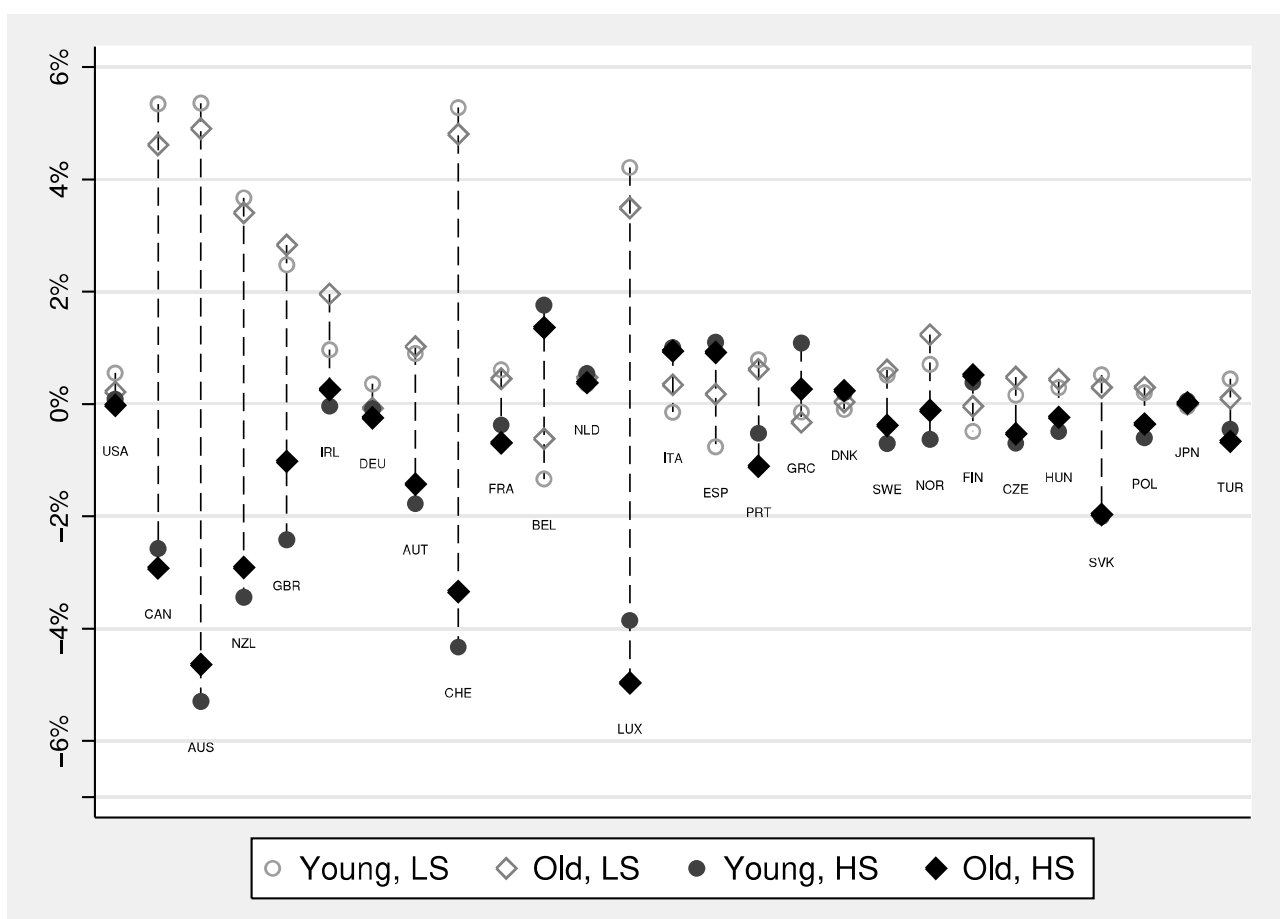

The figure plots equilibrium wage responses to immigration

Figure 8: Wage effects of emigration, 2000 - 2010 (\%), by age-education group

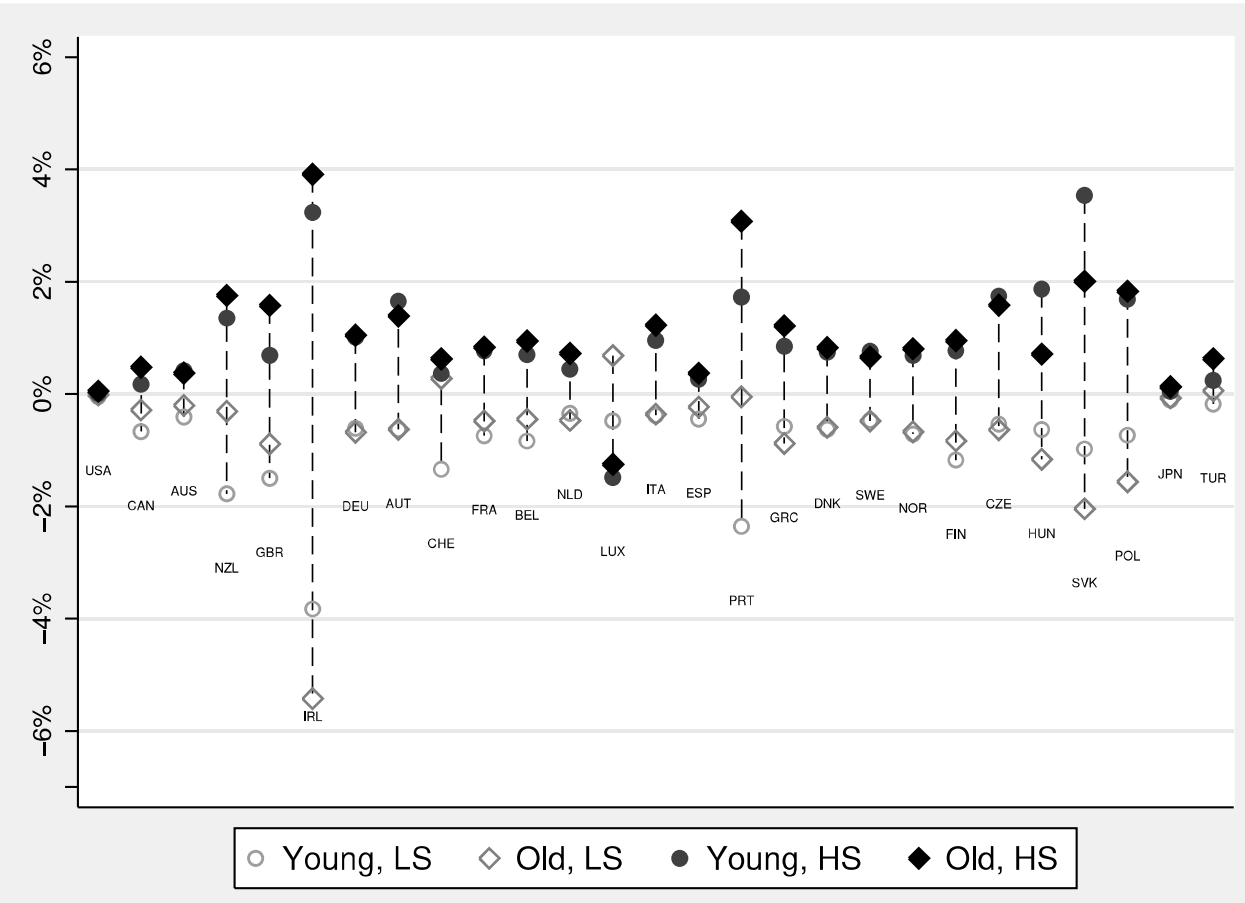

The figure plots equilibrium wage responses to emigration 
Figure 9a: Combined wage effects socio-demographic changes, immigration and emigration, $2000-2010$ (\%), for Old Low-Skilled

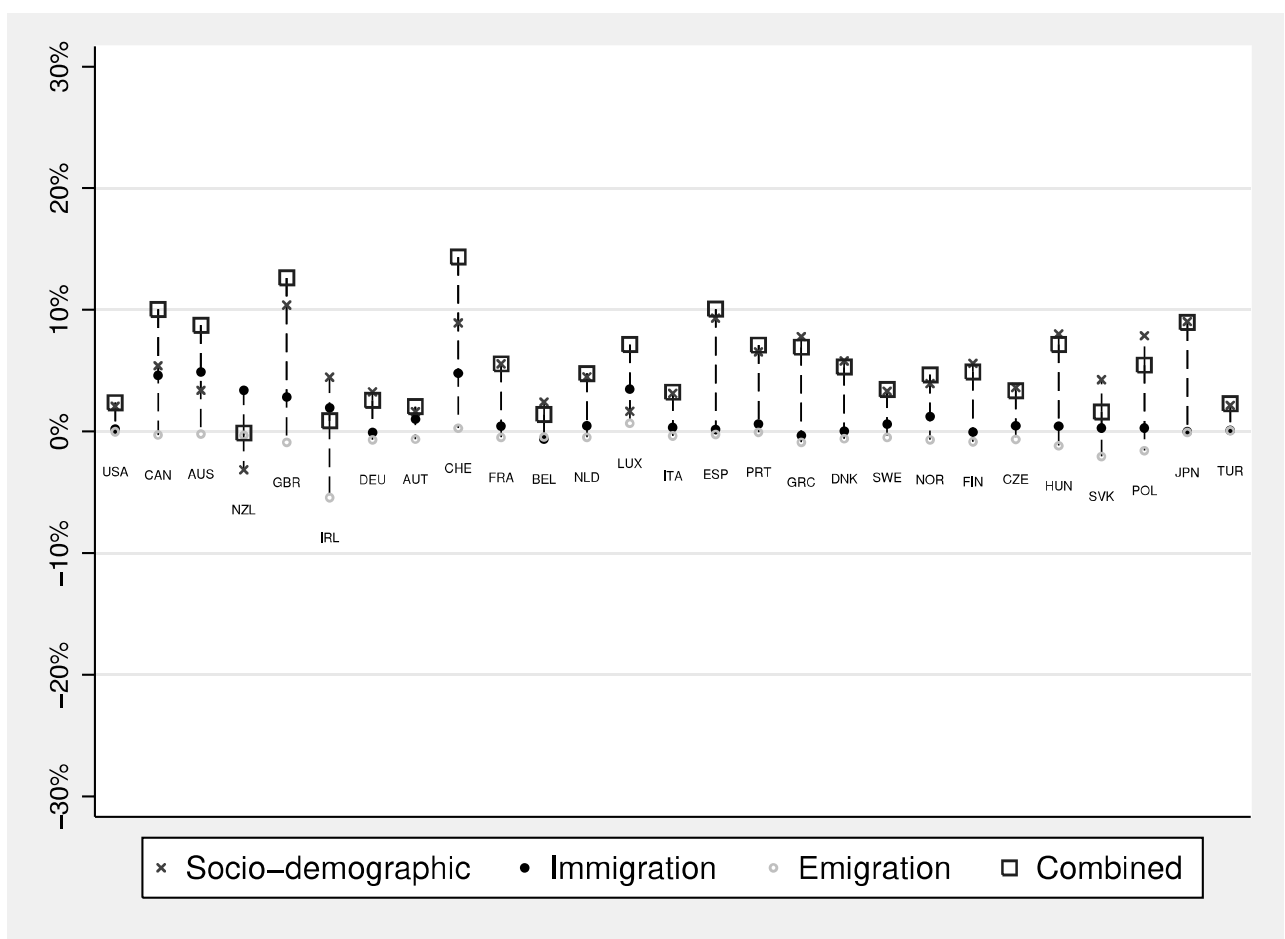

The figure plots equilibrium wage responses to overall changes in the structure of the labor force

Figure 9b: Combined wage effects socio-demographic changes, immigration and emigration, $2000-2010$ (\%), for Young Low-Skilled

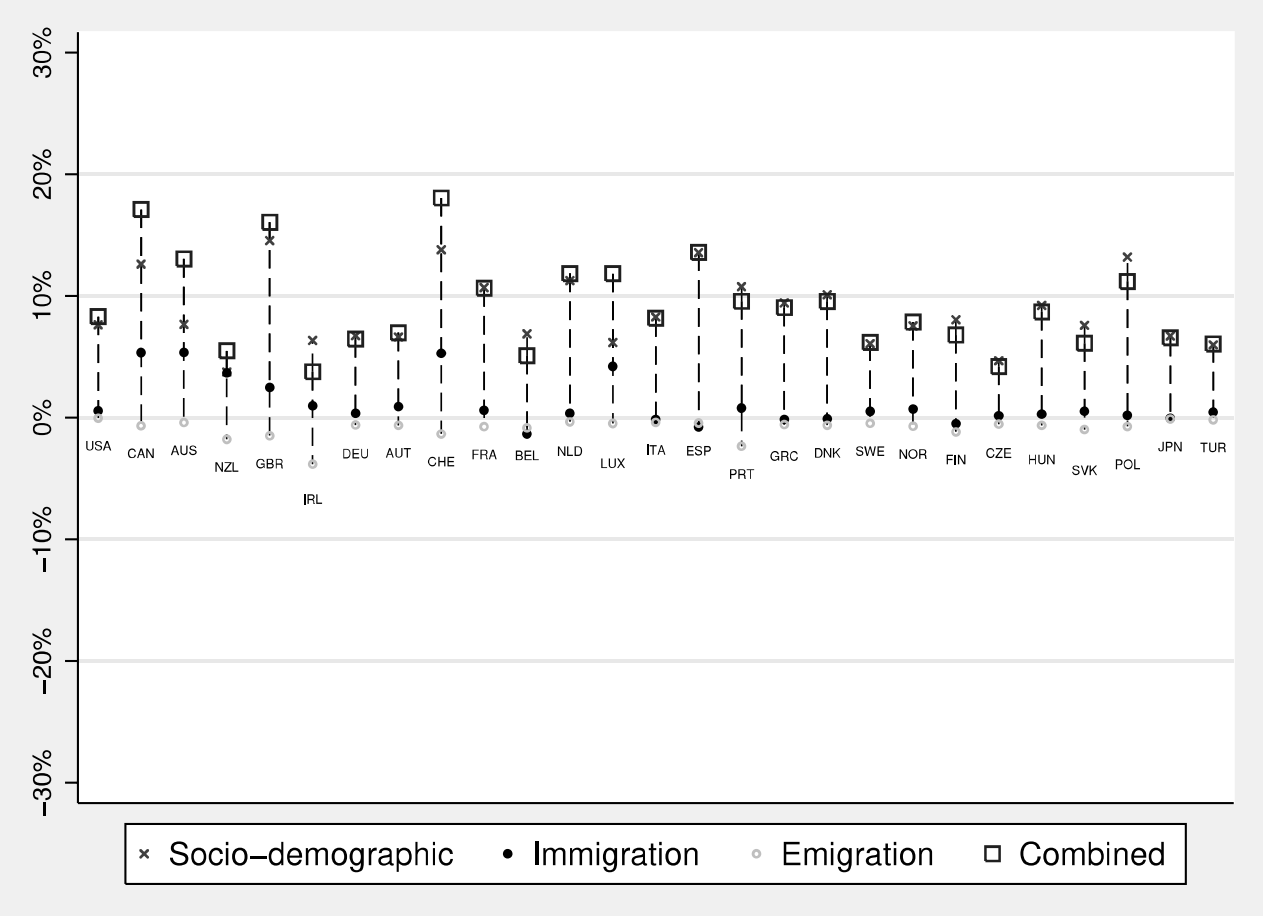

The figure plots equilibrium wage responses to overall changes in the structure of the labor force 
Figure 9c: Combined wage effects socio-demographic changes, immigration and emigration, $2000-2010$ (\%), for Old High-Skilled

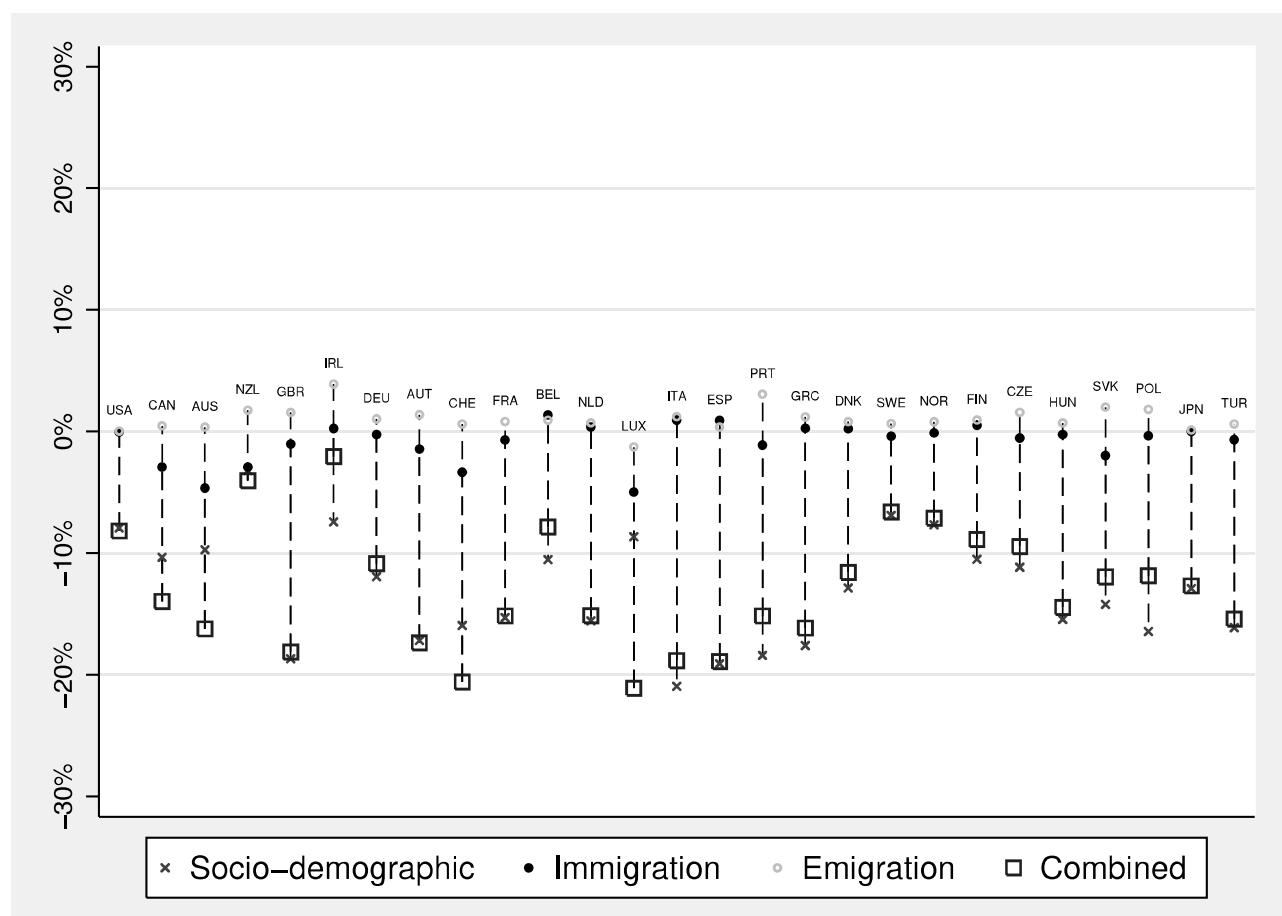

The figure plots equilibrium wage responses to overall changes in the structure of the labor force

Figure 9d: Combined wage effects socio-demographic changes, immigration and emigration, 2000 - 2010 (\%), for Young High-Skilled

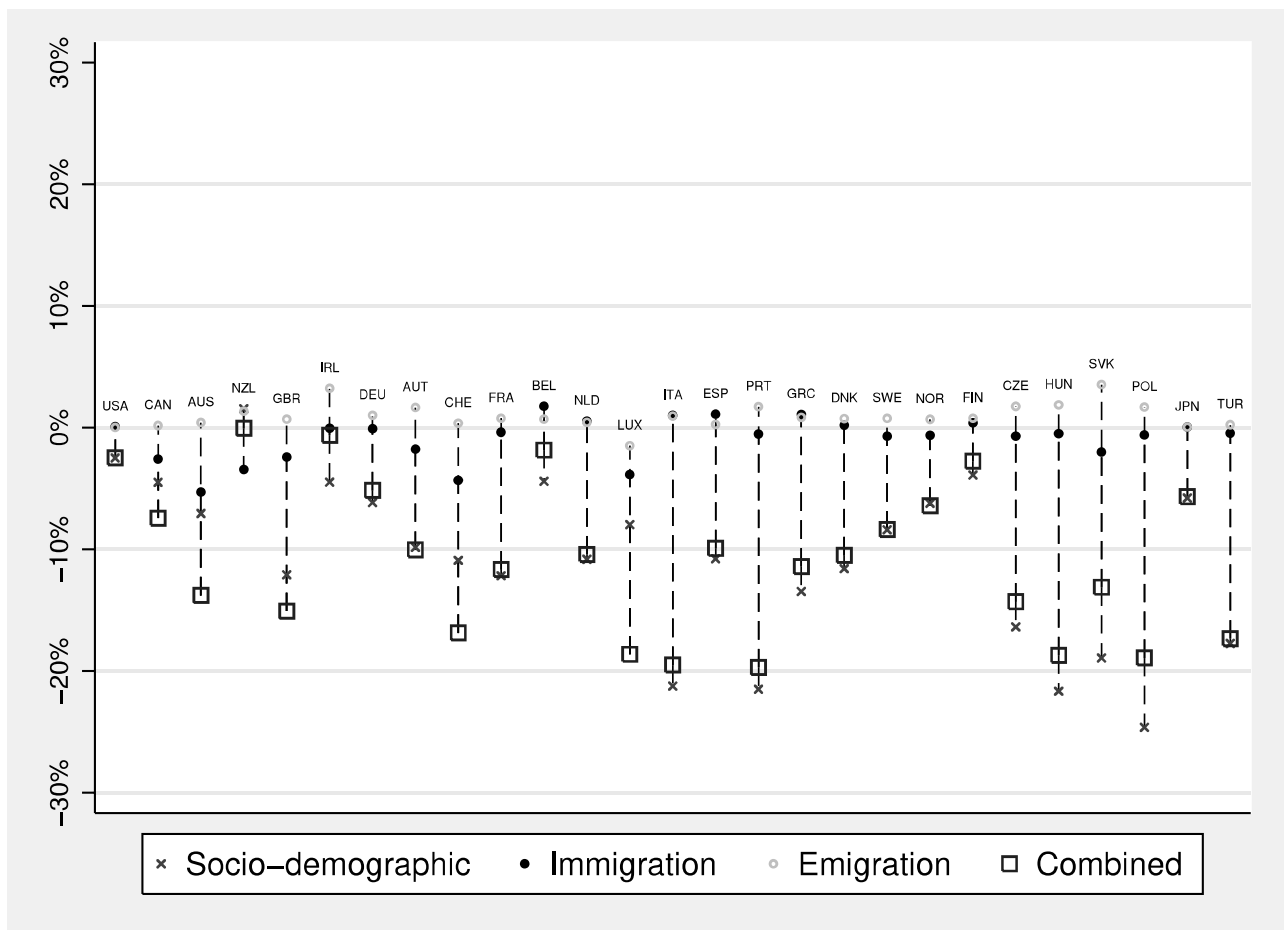

The figure plots equilibrium wage responses to overall changes in the structure of the labor force 
Figure 10: Robustness: Combined wage effects in the baseline vs. involuntary unemployment scenario

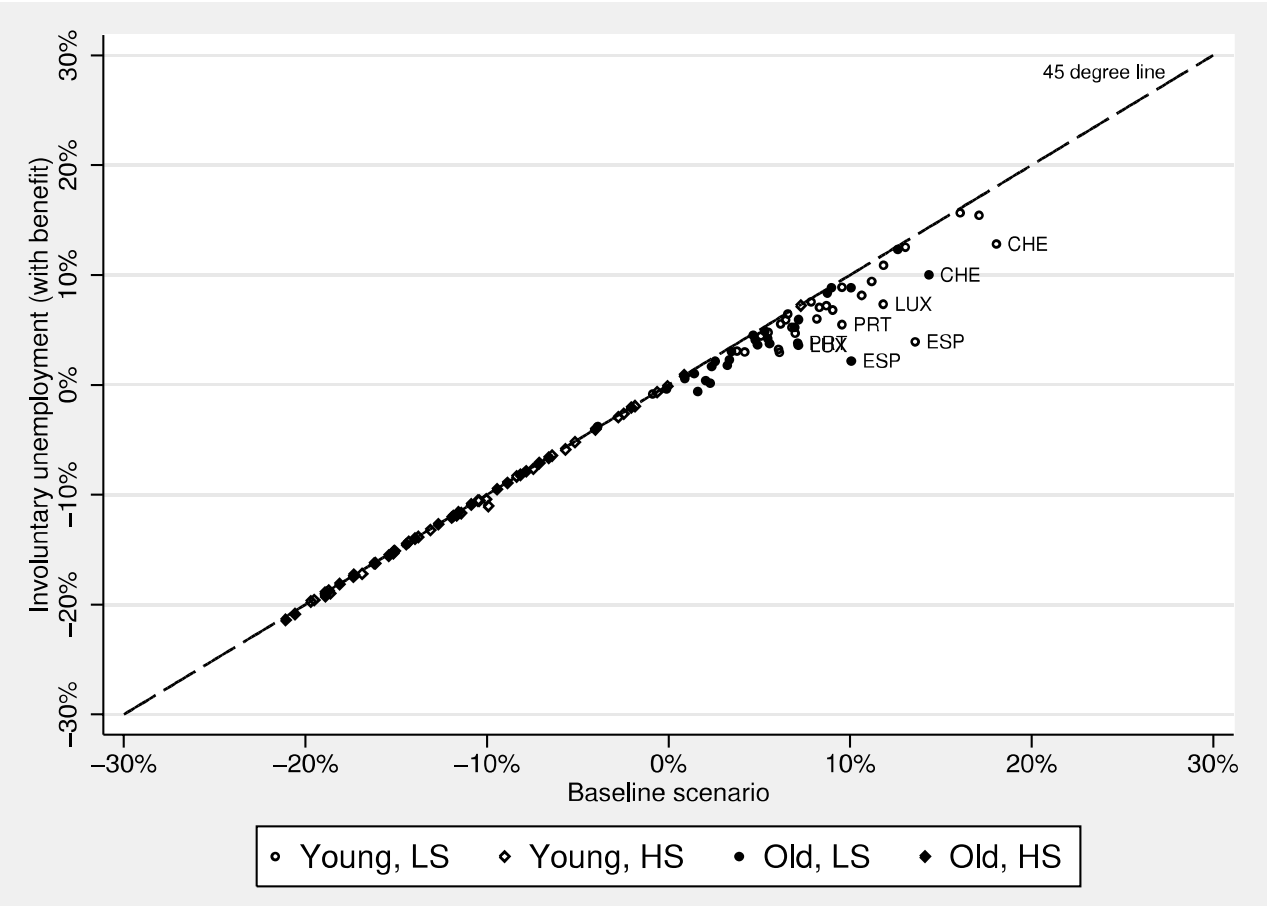

The figure contrasts equilibrium wage responses in the baseline scenario to those from a scenario where we allow for involuntary unemployment

Figure 11: Robustness: Combined wage effects in the baseline vs. fixed capital stock scenario

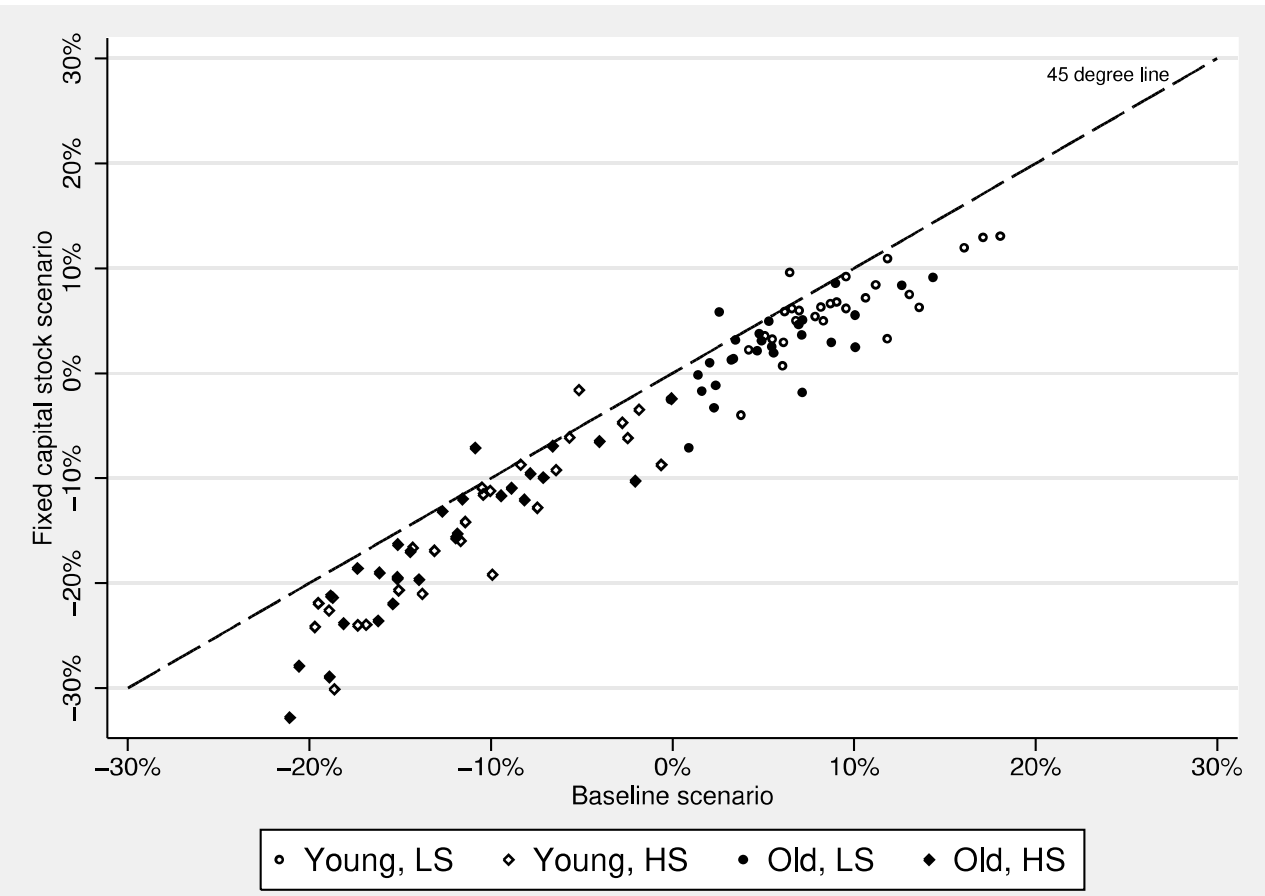

The figure contrasts equilibrium wage responses in the baseline scenario to those from a scenario where capital stock is fixed 
Figure 12: Robustness: Combined wage effects in the baseline vs. moderate technological change scenario
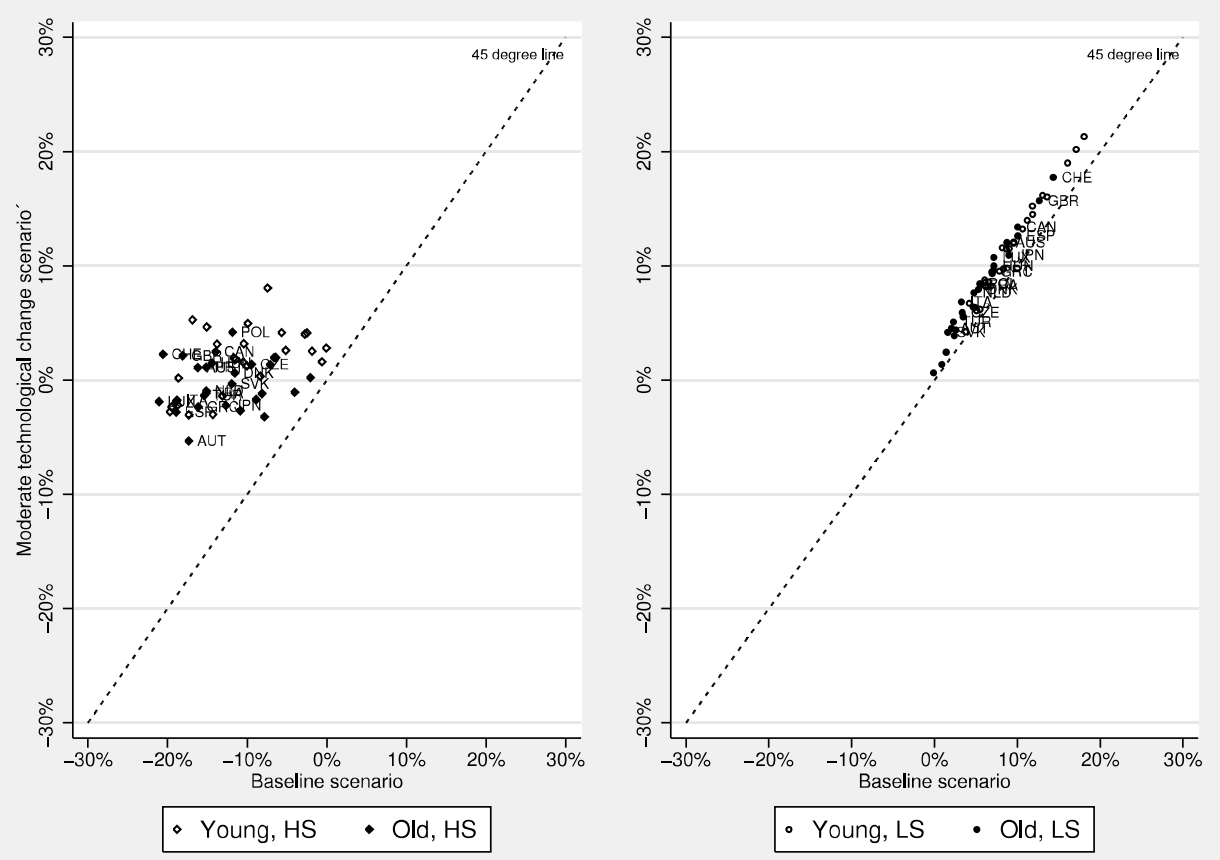

The figure contrasts equilibrium wage responses in the baseline scenario to those from a scenario where we allow for moderate technological change

Figure 13: Robustness: Combined wage effects in the baseline vs. strong technological change scenario
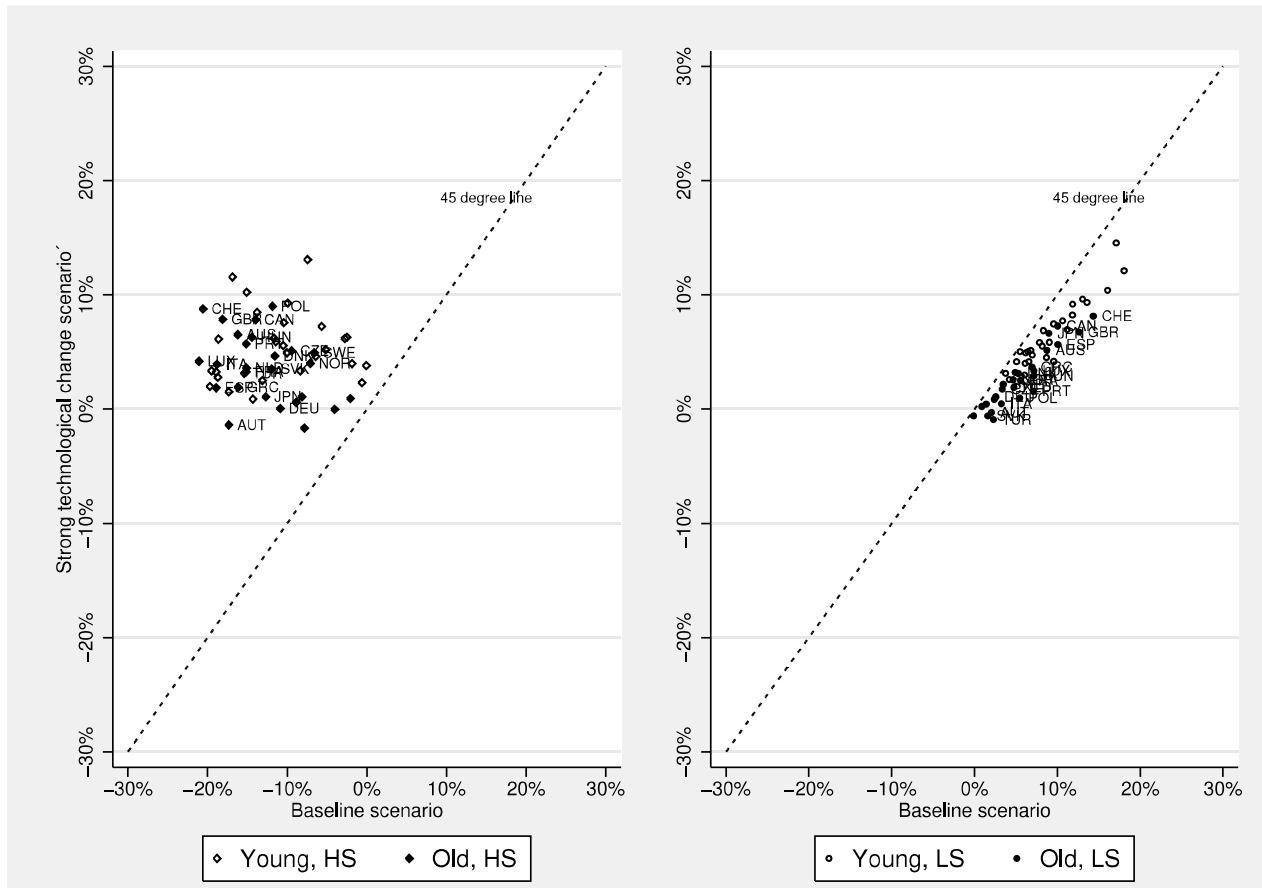

The figure contrasts equilibrium wage responses in the baseline scenario to those from a scenario where we allow for strong technological change 


\section{Tables}

Table 1: Age distribution of populations in 2010, \% (25+ only),

Natives

Immigrants

Emigrants

\begin{tabular}{lrrr|rrr|rrr}
\hline \hline & $25-44$ & $45-64$ & $65+$ & $25-44$ & $45-64$ & $65+$ & $25-44$ & $45-64$ & $65+$ \\
\hline \hline USA & 38.80 & 40.49 & 20.71 & 50.01 & 35.50 & 14.49 & 38.71 & 40.69 & 20.60 \\
CAN & 38.30 & 42.80 & 18.90 & 37.82 & 39.72 & 22.46 & 36.31 & 38.52 & 25.17 \\
AUS & 42.97 & 37.55 & 19.48 & 39.23 & 37.76 & 23.01 & 58.97 & 30.03 & 11.01 \\
NZL & 37.06 & 40.49 & 22.44 & 42.73 & 36.84 & 20.43 & 49.98 & 39.24 & 10.78 \\
GBR & 36.55 & 38.17 & 25.28 & 56.17 & 29.43 & 14.40 & 27.98 & 42.52 & 29.50 \\
IRL & 43.36 & 36.27 & 20.37 & 67.18 & 26.43 & 6.39 & 27.65 & 32.67 & 39.68 \\
DEU & 32.37 & 37.89 & 29.75 & 43.19 & 40.25 & 16.55 & 43.18 & 33.49 & 23.33 \\
AUT & 42.04 & 43.66 & 14.30 & 53.01 & 37.67 & 9.33 & 20.82 & 39.26 & 39.92 \\
CHE & 40.54 & 44.30 & 15.15 & 52.10 & 38.42 & 9.48 & 52.45 & 33.17 & 14.38 \\
FRA & 38.70 & 36.90 & 24.40 & 36.39 & 41.20 & 22.41 & 50.37 & 31.66 & 17.97 \\
BEL & 35.72 & 38.44 & 25.84 & 48.43 & 35.76 & 15.81 & 39.46 & 38.47 & 22.08 \\
NLD & 36.24 & 40.53 & 23.22 & 50.75 & 38.72 & 10.53 & 26.54 & 41.57 & 31.89 \\
LUX & 35.27 & 37.86 & 26.87 & 51.56 & 36.44 & 12.00 & 41.42 & 35.66 & 22.92 \\
ITA & 34.01 & 36.73 & 29.26 & 61.20 & 31.19 & 7.61 & 19.29 & 40.46 & 40.25 \\
ESP & 39.93 & 35.21 & 24.86 & 62.82 & 28.84 & 8.33 & 30.82 & 36.72 & 32.46 \\
PRT & 36.37 & 36.30 & 27.33 & 61.42 & 30.32 & 8.26 & 37.34 & 46.73 & 15.94 \\
GRC & 36.60 & 34.77 & 28.63 & 59.59 & 31.03 & 9.38 & 18.06 & 43.15 & 38.79 \\
DNK & 35.22 & 39.14 & 25.63 & 57.18 & 32.61 & 10.21 & 33.64 & 34.38 & 31.98 \\
SWE & 35.12 & 36.77 & 28.12 & 46.70 & 35.73 & 17.57 & 52.59 & 30.93 & 16.47 \\
NOR & 37.21 & 38.48 & 24.32 & 62.58 & 30.05 & 7.37 & 31.87 & 33.30 & 34.83 \\
FIN & 33.71 & 40.80 & 25.50 & 64.87 & 28.14 & 6.98 & 19.39 & 46.07 & 34.54 \\
CZE & 41.01 & 37.59 & 21.39 & 45.42 & 32.30 & 22.28 & 35.29 & 32.78 & 31.94 \\
HUN & 39.87 & 37.42 & 22.71 & 41.43 & 28.73 & 29.84 & 34.78 & 26.55 & 38.67 \\
POL & 41.56 & 40.44 & 18.00 & 9.18 & 12.01 & 78.81 & 51.76 & 33.15 & 15.09 \\
SVK & 44.70 & 37.86 & 17.44 & 25.24 & 44.87 & 29.89 & 43.21 & 30.17 & 26.62 \\
JPN & 34.55 & 35.25 & 30.20 & 63.06 & 27.48 & 9.46 & 49.58 & 36.64 & 13.78 \\
TUR & 58.93 & 34.81 & 6.26 & 42.77 & 44.52 & 12.71 & 53.05 & 35.87 & 11.09 \\
\hline \hline
\end{tabular}

Table reports the age-group breakdown of all those of age 25 or more 


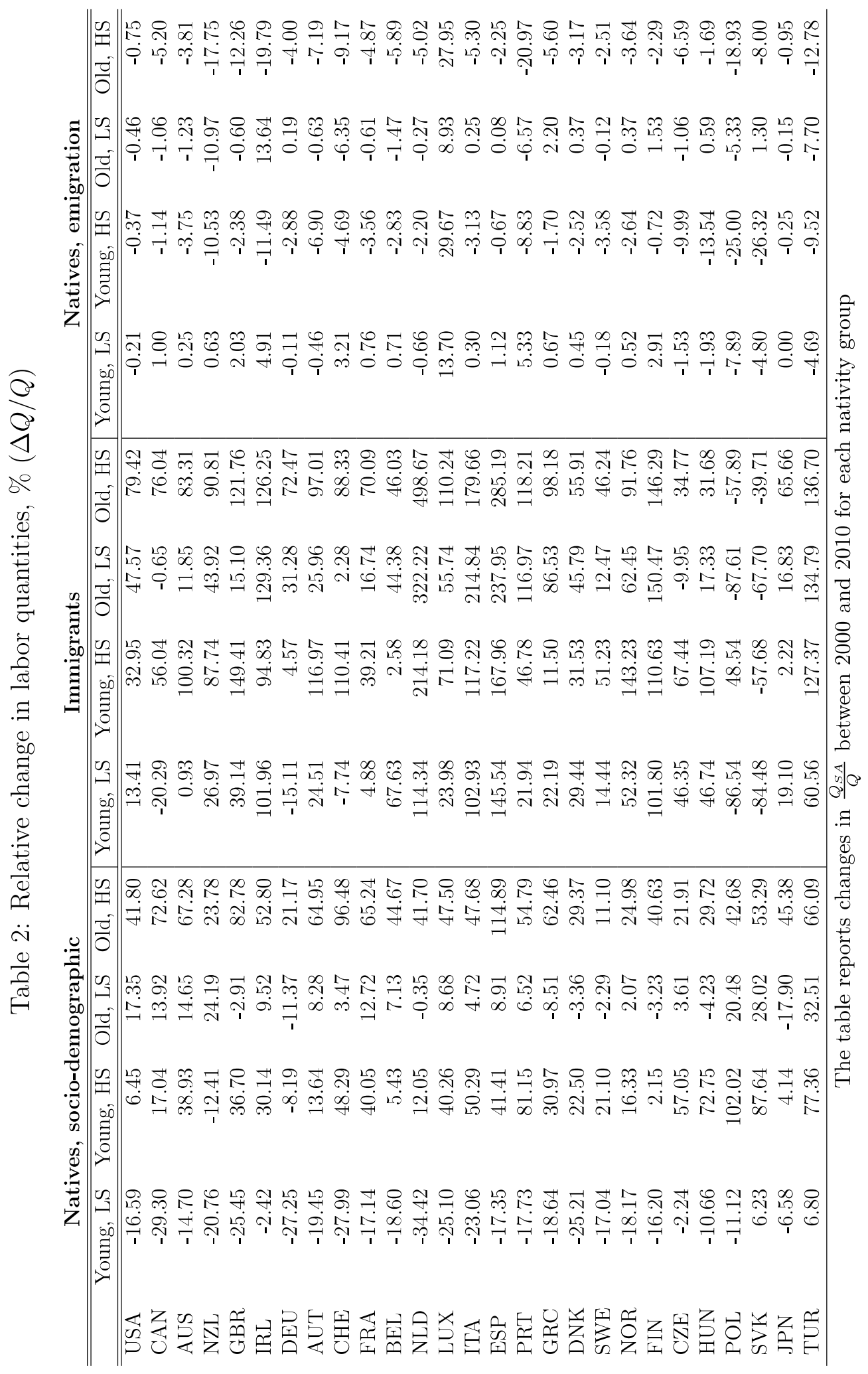


Table 3: Parameter values used in simulation

\begin{tabular}{lc}
\hline \hline$\delta_{s}:$ Elasticity of substitution between the high and low skilled & 1.75 \\
$\delta_{a}:$ Elasticity of substitution between the old and young & 5 \\
$\delta_{m}:$ Elasticity of substitution between immigrants and natives & 20 \\
$\gamma:$ Elasticity of labor supply & .10 \\
\hline \hline Parameters used in the intermediary scenario in DOP; $\delta_{a}$ comes from Card and Lemieux (2001)
\end{tabular}


Table 4: Extensions with changes in elasticities, median values (minimum, maximum in parentheses)

\begin{tabular}{|c|c|c|c|c|c|}
\hline Scenario & & Young, LS & Young, HS & Old, LS & Old, $H S$ \\
\hline & Total & $\begin{array}{c}8.23 \\
(-0.88 ; 18.05)\end{array}$ & $\begin{array}{c}-10.46 \\
(-19.71 ; 7.28)\end{array}$ & $\begin{array}{c}4.84 \\
(-3.89 ; 14.34)\end{array}$ & $\begin{array}{c}-13.33 \\
(-21.09 ; 0.87)\end{array}$ \\
\hline & Socio-demographic & $\begin{array}{c}7.65 \\
(-0.69 ; 14.55)\end{array}$ & $\begin{array}{c}-10.31 \\
(-24.63 ; 7.92)\end{array}$ & $\begin{array}{c}4.37 \\
(-4.74 ; 10.39)\end{array}$ & $\begin{array}{c}-12.88 \\
(-20.93 ; 0.34)\end{array}$ \\
\hline \multirow[t]{4}{*}{ Baseline } & Immigration & $\begin{array}{c}0.48 \\
(-1.34 ; 5.36)\end{array}$ & $\begin{array}{c}-0.47 \\
(-5.3 ; 1.76)\end{array}$ & $\begin{array}{c}0.45 \\
(-0.62 ; 4.9)\end{array}$ & $\begin{array}{c}-0.30 \\
(-4.97 ; 1.36)\end{array}$ \\
\hline & Emigration & $\begin{array}{c}-0.63 \\
(-3.83 ;-0.04)\end{array}$ & $\begin{array}{c}0.75 \\
(-1.48 ; 3.54)\end{array}$ & $\begin{array}{c}-0.48 \\
(-5.43 ; 0.68)\end{array}$ & $\begin{array}{c}0.83 \\
(-1.25 ; 3.91)\end{array}$ \\
\hline & Total & $\begin{array}{c}6.03 \\
(0.95 ; 13.96)\end{array}$ & $\begin{array}{c}-7.27 \\
(-22.38 ; 4.37)\end{array}$ & $\begin{array}{c}4.32 \\
(-4.13 ; 10.85)\end{array}$ & $\begin{array}{c}-9.75 \\
(-20.99 ;-1.81)\end{array}$ \\
\hline & Socio-demographic & $\begin{array}{c}7.03 \\
(-0.45 ; 13.1)\end{array}$ & $\begin{array}{c}-8.84 \\
(-21.84 ; 7.24)\end{array}$ & $\begin{array}{c}3.48 \\
(-4.49 ; 8.87)\end{array}$ & $\begin{array}{c}-11.63 \\
(-18.31 ;-0.4)\end{array}$ \\
\hline \multirow[t]{4}{*}{$\sigma_{s}=2$} & Immigration 0.42 & $\begin{array}{c}-0.39 \\
(-1.18 ; 4.76)\end{array}$ & $\begin{array}{c}0.40 \\
(-4.56 ; 1.58)\end{array}$ & $\begin{array}{c}-0.26 \\
(-0.46 ; 4.3)\end{array}$ & $(-4.28 ; 1.17)$ \\
\hline & Emigration & $\begin{array}{c}-1.65 \\
(-13.62 ; 2.13)\end{array}$ & $\begin{array}{c}1.20 \\
(-3.42 ; 8.71)\end{array}$ & $\begin{array}{c}-0.33 \\
(-4.73 ; 1.88)\end{array}$ & $\begin{array}{c}1.47 \\
(-3.74 ; 5.64)\end{array}$ \\
\hline & Total & $\begin{array}{c}7.56 \\
(-1.18 ; 17.57)\end{array}$ & $\begin{array}{c}-10.88 \\
(-19.5 ; 6.81)\end{array}$ & $\begin{array}{c}5.46 \\
(-3.34 ; 14.84)\end{array}$ & $\begin{array}{c}-13.17 \\
(-20.53 ; 2.22)\end{array}$ \\
\hline & Socio-demographic & $\begin{array}{c}7.18 \\
(-1.08 ; 13.99)\end{array}$ & $\begin{array}{c}-10.96 \\
(-24.08 ; 7.38)\end{array}$ & $\begin{array}{c}4.77 \\
(-3.99 ; 10.97)\end{array}$ & $\begin{array}{c}-12.37 \\
(-21.03 ; 1.95)\end{array}$ \\
\hline \multirow[t]{4}{*}{$\sigma_{a}=7$} & Immigration & $\begin{array}{c}0.44 \\
(-1.2 ; 5.27)\end{array}$ & $\begin{array}{c}-0.47 \\
(-5.2 ; 1.71)\end{array}$ & $\begin{array}{c}0.41 \\
(-0.75 ; 4.98)\end{array}$ & $\begin{array}{c}-0.37 \\
(-4.8 ; 1.46)\end{array}$ \\
\hline & Emigration & $\begin{array}{c}-0.64 \\
(-3.76 ; 0.07)\end{array}$ & $\begin{array}{c}0.74 \\
(-0.77 ; 3.52)\end{array}$ & $\begin{array}{c}-0.48 \\
(-5.34 ; 0.85)\end{array}$ & $\begin{array}{c}0.82 \\
(-0.65 ; 3.78)\end{array}$ \\
\hline & Total & $\begin{array}{c}7.87 \\
(-0.91 ; 17.77)\end{array}$ & $\begin{array}{c}-10.75 \\
(-19.84 ; 7.21)\end{array}$ & $\begin{array}{c}4.65 \\
(-3.92 ; 14.28)\end{array}$ & $\begin{array}{c}-13.37 \\
(-21.21 ; 0.8)\end{array}$ \\
\hline & Socio-demographic & $\begin{array}{c}7.53 \\
(-0.72 ; 14.47)\end{array}$ & $\begin{array}{c}-9.90 \\
(-24.4 ; 7.86)\end{array}$ & $\begin{array}{c}4.40 \\
(-4.77 ; 10.43)\end{array}$ & $\begin{array}{c}-12.86 \\
(-20.78 ; 0.32)\end{array}$ \\
\hline \multirow[t]{2}{*}{$\sigma_{m}=1000$} & Immigration & $\begin{array}{c}0.38 \\
(-1.75 ; 5.57)\end{array}$ & $\begin{array}{c}-0.64 \\
(-6.45 ; 1.74)\end{array}$ & $\begin{array}{c}0.42 \\
(-0.8 ; 4.72)\end{array}$ & $\begin{array}{c}-0.37 \\
(-6.67 ; 1.21)\end{array}$ \\
\hline & Emigration & $\begin{array}{c}-0.64 \\
(-3.76 ; 0.07)\end{array}$ & $\begin{array}{c}0.74 \\
(-0.77 ; 3.52)\end{array}$ & $\begin{array}{c}-0.48 \\
(-5.34 ; 0.85)\end{array}$ & $\begin{array}{c}0.82 \\
(-0.65 ; 3.78)\end{array}$ \\
\hline
\end{tabular}

The table reports equilibrium wage responses when we vary the parameter values in table 3 


\section{Appendix}

\section{A Immigration: variations in stocks versus inflows}

As explained in Section 3, we use the DIOC database to characterize the socio-demographic changes that have taken place between the years 2000 and 2010. In particular, the results presented in Section 4.2 highlight the wage effects that are due to the (net) variations in the stock of immigrants. These variations result from three forces: new migrant inflows, return migration, mortality. One might wonder whether the effects depicted in Figure 7 hold true when focusing on (gross) inflows of immigrants over the same period.

The DIOC database allows identifying the origin, education, and duration of stay of the population. In particular, we can identify the origin and education structures of immigrants who arrived between the years 2000 and 2010 and who were still living in the destination country in 2010. As duration of stay cannot be jointly identified by age group, we assume all recent immigrants are young (i.e. aged 25 to 44). Figure A.1 compares the wage effects induced by the net variation in the immigrant stock (horizontal axis) with those induced by the gross inflow (vertical axis). In most countries, the results are almost identical. The few exceptions are for countries that have experienced drastic increases in immigration. Recent immigration makes the population younger, which increases the age premium and the competition among younger workers.

\section{[INSERT FIGURE A.1 HERE]}

\section{B Elasticities of substitution across groups}

Our model assumes that the aggregate labor composite $q$ can be modeled as a nested CES (constant elasticity of substitution) function of different worker types. From Eqs. (13), (14) and (15), this means that a one percent increase in the ratio of employment levels within a nest induces a constant response in the wage ratio within the same nest (equal to $-1 / \sigma_{M},-1 / \sigma_{A}$, or $-1 / \sigma_{S}$ ), whatever the intital employment levels. However, the elasticity of substitution across groups (i.e. between workers belonging to different nests) is not constant. It depends on initial structure of employment and on the size of the shock.

One way to explore the cross-elasticities across nests is to only change the labor supply of one group and see how the wages of different groups respond. Let $\sigma_{S A M}$ denote the cross-elasticity between group (SAM) and any other chosen group (SAN). It follows that:

$$
\frac{-1}{\sigma_{S A M}}=\frac{d \ln \left(\frac{w_{S A M}}{w_{S A N}}\right)}{d \ln \left(\frac{Q_{S A M}}{Q_{S A N}}\right)}
$$


Note that $d \ln \left(\frac{w_{S A M}}{w_{S A N}}\right)=d \ln \left(w_{S A M}\right)-d \ln \left(w_{S A N}\right)$ and $d \ln \left(w_{S A M}\right)=\frac{\Delta w_{S A M}}{w_{S A M}}$ Now, let's assume that only the stock of the young high-skilled natives (YHN) changes by $1 \%$ while those of other groups remain unchanged. In other words, $d \ln \left(\frac{Q_{S A M}}{Q_{S A N}}\right)=0-0.01=-0.01$ This means:

$$
\sigma_{S A M}=\frac{0.01}{d \ln \left(\frac{w_{S \Lambda M}}{w_{Y H N}}\right)}
$$

We now simulate wage responses to this $1 \%$ increase in the stock of young high-skilled (YHN) while maintaining the stocks of other groups unchanged. We then use the above formula to compute the elasticities of interest, for exposition. These are reported in the Appendix Table A1 below.

[INSERT TABLE A.1 HERE]

\section{Decomposing the socio-demographic effects}

A natural question is how to split the combined effect of socio-demographic change into separate "ageing" and "educational change" components. This is not a simple task since the changes in the relative magnitudes of each of our four labor groups are interrelated. The increase in the stocks of the high-skilled workers may arise from both ageing (as younger high-skilled workers move to the older age group while the older low-skilled retire) and an increase in the number of people with more education (as the next generation of younger people receive more education than the previous one). In order to separate these two effects, we need to make certain assumptions about the demographic and education changes.

We start our decomposition by assuming that the change in the stock of any given labor category can be expressed as the sum of the changes due to ageing and due to education. These relationships can be expressed as the following, where $e$ denotes education and $a$ denotes ageing:

$$
\Delta Q_{S A N}^{e}+\Delta Q^{a}{ }_{S A N}=\Delta Q_{S A N}
$$

In order to solve this system of four equations and eight unknowns, we need to make several simplifying assumptions. First, the increase in the stocks of low-skilled workers, whether old or young, can only arise from the increase in age within the population between 2000 and 2010. This is merely because years of schooling for a given individual does not decline over time as there is no de-skilling. By implication, $\Delta Q_{L Y N}^{e}=\Delta Q^{e}{ }_{L O N}=0$.

Then we define $R_{o n}=Q_{H O N} / Q_{L O N}$; and $R_{y n}=Q_{H Y N} / Q_{L Y N}$. We later make the simplifying assumption that, if there were no changes in educational composition between 2000 and 2010 , then $R_{y n}$ and $R_{o n}$ in 2010 would take the same values they did in 2000 . This assumption isolates the changes due to educationa and gives us the following equations: 


$$
\left\{\begin{array}{l}
\Delta Q^{a}{ }_{L Y N}=\Delta Q_{L Y N} \\
\Delta Q^{a}{ }_{L O N}=\Delta Q_{L O N} \\
\Delta Q^{e}{ }_{H Y N}+R_{y n} \Delta Q^{a}{ }_{L Y N}=\Delta Q_{H Y N} \\
\Delta Q_{H O N}^{e}+R_{o n} \Delta Q^{a}{ }_{L O N}=\Delta Q_{H O N}
\end{array}\right.
$$

with

$$
\left\{\begin{aligned}
\Delta Q^{a}{ }_{H Y N} & =R_{y n} \Delta Q^{a}{ }_{L Y N} \\
\Delta Q^{a}{ }_{H O N} & =R_{o n} \Delta Q^{a}{ }_{L O N}
\end{aligned}\right.
$$

We compute $R_{y n}$ and $R_{o n}$ using data from 2000. Only the last two equations then require solving. We subsquently use $\Delta Q^{a}{ }_{\text {lyn }}, \Delta Q^{a}{ }_{L O N}, \Delta Q_{H Y N}^{e}, \Delta Q_{H Y N}^{a}, \Delta Q_{H O N}^{e}$ and $\Delta Q^{a}{ }_{H O N}$ to obtain the wage effects of interest for each of our four groups.

Figure 6 presents how these age and education components differ for each labor group in the OECD countries in our sample.

\section{Supplementary tables}

The tables provided in this Section give the results of the main analysis (see Section ??) for individual countries.

[INSERT TABLE A.2 HERE]

[INSERT TABLE A.3 HERE]

[INSERT TABLE A.4 HERE]

[INSERT TABLE A.5 HERE] 
Appendix Figure A1: Robustness of immigration wage effects: Net changes in stock vs. gross inflows

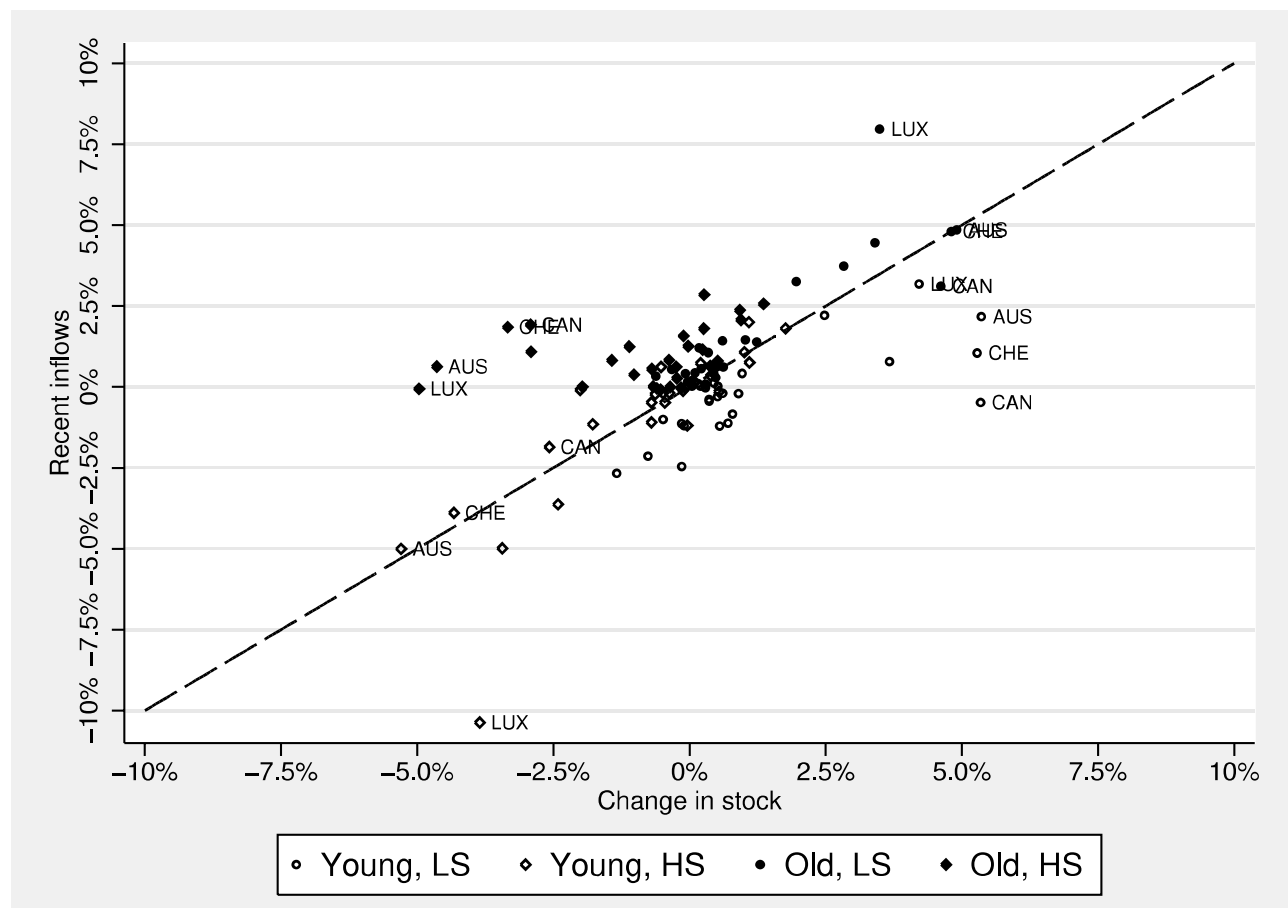

The figure contrasts equilibrium wage responses due to immigration when using net changes in stock vs. gross inflows between 2000 and 2010 


\section{Appendix Tables}

Table A.1: Approximates of elasticity of substitution across labor groups in \%, assuming $d Q_{H Y N} / Q_{H Y N}=1 \%$

\begin{tabular}{lcccccccc}
\hline \hline & \multicolumn{9}{c}{ Natives } & \multicolumn{5}{c}{ Immigrants } \\
\hline \hline & Young, LS & Young, HS & Old, LS & Old, HS & Young, LS & Young, HS & Old, LS & Old, HS \\
\hline USA & 3.3 & - & 3.3 & 6.2 & 3.3 & 21.5 & 3.3 & 6.2 \\
CAN & 4.2 & - & 4.2 & 7.9 & 4.2 & 23.7 & 4.2 & 7.9 \\
AUS & 5.5 & - & 5.5 & 10.4 & 5.5 & 28.1 & 5.5 & 10.4 \\
NZL & 3.6 & - & 3.6 & 6.7 & 3.6 & 17.7 & 3.6 & 6.7 \\
GBR & 4.3 & - & 4.3 & 8.5 & 4.3 & 27.6 & 4.3 & 8.5 \\
IRL & 3.9 & - & 3.9 & 8.5 & 3.9 & 26.3 & 3.9 & 8.5 \\
DEU & & & & & & & & \\
AUT & 3.3 & - & 3.3 & 6.6 & 3.3 & 23.0 & 3.3 & 6.6 \\
CHE & 5.4 & - & 5.4 & 10.2 & 5.4 & 29.9 & 5.4 & 10.2 \\
FRA & 3.5 & - & 3.5 & 7.6 & 3.5 & 28.3 & 3.5 & 7.6 \\
BEL & 2.8 & - & 2.8 & 5.8 & 2.8 & 21.3 & 2.8 & 5.8 \\
NLD & - & - & - & - & - & - & - & - \\
LUX & 6.6 & - & 6.6 & 12.5 & 6.6 & 28.3 & 6.6 & 12.5 \\
ITA & 3.8 & - & 3.8 & 8.3 & 3.8 & 30.4 & 3.8 & 8.3 \\
ESP & 3.6 & - & 3.6 & 7.8 & 3.6 & 28.6 & 3.6 & 7.8 \\
PRT & 4.7 & - & 4.7 & 10.5 & 4.7 & 36.6 & 4.7 & 10.5 \\
GRC & 3.4 & - & 3.4 & 7.3 & 3.4 & 26.5 & 3.4 & 7.3 \\
DNK & 3.4 & - & 3.4 & 6.6 & 3.4 & 24.8 & 3.4 & 6.6 \\
SWE & 3.6 & - & 3.6 & 6.9 & 3.6 & 24.5 & 3.6 & 6.9 \\
NOR & 3.3 & - & 3.3 & 6.7 & 3.3 & 23.5 & 3.3 & 6.7 \\
FIN & 2.8 & - & 2.8 & 5.4 & 2.8 & 20.7 & 2.8 & 5.4 \\
CZE & 4.0 & - & 4.0 & 8.5 & 4.0 & 31.7 & 4.0 & 8.5 \\
HUN & 4.2 & - & 4.2 & 9.3 & 4.2 & 34.9 & 4.2 & 9.3 \\
POL & 4.5 & - & 4.5 & 10.4 & 4.5 & 40.8 & 4.5 & 10.4 \\
SVK & 4.4 & - & 4.4 & 9.8 & 4.4 & 37.9 & 4.4 & 9.8 \\
JPN & & & & & & & & \\
MEX & 1.4 & - & 1.4 & 2.9 & 1.4 & 10.9 & 1.4 & 2.9 \\
TUR & 4.0 & - & 4.0 & 9.5 & 4.0 & 35.8 & 4.0 & 9.5 \\
\hline \hline & & - & -6.5 & & & & & \\
\hline
\end{tabular}

The table illustrates elasticity of substitution value across nests 
Table A.2: Baseline Scenario - wage effects of socio-demographic (age-education) changes $(\%)$

\begin{tabular}{lcccc}
\hline \hline & Young, LS & Young, HS & Old, LS & Old, HS \\
\hline \hline USA & 7.63 & -2.49 & 2.08 & -7.92 \\
CAN & 12.62 & -4.49 & 5.41 & -10.33 \\
AUS & 7.66 & -7.06 & 3.39 & -9.71 \\
NZL & 3.75 & 1.55 & -3.14 & -3.22 \\
GBR & 14.55 & -12.10 & 10.39 & -18.68 \\
IRL & 6.34 & -4.48 & 4.47 & -7.42 \\
DEU & 6.73 & -6.15 & 3.26 & -11.92 \\
AUT & 6.63 & -9.84 & 1.64 & -17.17 \\
CHE & 13.80 & -10.91 & 8.94 & -15.93 \\
FRA & 10.69 & -12.17 & 5.57 & -15.29 \\
BEL & 6.88 & -4.41 & 2.43 & -10.52 \\
NLD & 11.27 & -10.82 & 4.50 & -15.56 \\
LUX & 6.17 & -7.98 & 1.67 & -8.64 \\
ITA & 8.27 & -21.24 & $3.14 \%$ & -20.93 \\
ESP & 13.55 & -10.78 & 9.33 & -19.08 \\
PRT & 10.76 & -21.50 & 6.55 & -18.39 \\
GRC & 9.42 & -13.47 & 7.81 & -17.59 \\
DNK & 10.10 & -11.59 & 5.81 & -12.85 \\
SWE & 6.08 & -8.40 & 3.32 & -6.88 \\
NOR & 7.54 & -6.22 & 3.95 & -7.66 \\
FIN & 8.04 & -3.90 & 5.61 & -10.49 \\
CZE & 4.68 & -16.38 & 3.62 & -11.15 \\
HUN & 9.22 & -21.66 & 8.03 & -15.43 \\
POL & 13.20 & -24.63 & 7.88 & -16.43 \\
SVK & 7.59 & -18.93 & 4.26 & -14.20 \\
JPN & 6.71 & -5.79 & 9.05 & -12.90 \\
TUR & 5.98 & -17.74 & 2.16 & -16.11 \\
\hline \hline The table reports values of the wage effects depicted in Figure
\end{tabular}


Table A.3: Baseline scenario - wage effects of immigration (\%)

\begin{tabular}{lcccc}
\hline \hline & Young, LS & Young, HS & Old, LS & Old, HS \\
\hline \hline USA & 0.55 & 0.09 & 0.22 & -0.02 \\
CAN & 5.34 & -2.58 & 4.61 & -2.92 \\
AUS & 5.36 & -5.30 & 4.90 & -4.64 \\
NZL & 3.67 & -3.44 & 3.40 & -2.91 \\
GBR & 2.48 & -2.42 & 2.83 & -1.02 \\
IRL & 0.97 & -0.04 & 1.96 & 0.26 \\
DEU & 0.36 & -0.08 & -0.07 & -0.25 \\
AUT & 0.90 & -1.78 & 1.02 & -1.43 \\
CHE & 5.28 & -4.33 & 4.80 & -3.34 \\
FRA & 0.61 & -0.37 & 0.45 & -0.69 \\
BEL & -1.34 & 1.76 & -0.62 & 1.36 \\
NLD & 0.36 & 0.54 & 0.47 & 0.38 \\
LUX & 4.21 & -3.85 & 3.49 & -4.97 \\
ITA & -0.15 & 1.01 & 0.34 & 0.94 \\
ESP & -0.76 & 1.10 & 0.18 & 0.92 \\
PRT & 0.79 & -0.52 & 0.62 & -1.11 \\
GRC & -0.14 & 1.09 & -0.33 & 0.27 \\
DNK & -0.10 & 0.20 & 0.04 & 0.24 \\
SWE & 0.51 & -0.70 & 0.61 & -0.38 \\
NOR & 0.71 & -0.63 & 1.23 & -0.12 \\
FIN & -0.49 & 0.38 & -0.04 & 0.52 \\
CZE & 0.16 & -0.70 & 0.48 & -0.53 \\
HUN & 0.29 & -0.49 & 0.44 & -0.24 \\
POL & 0.20 & -0.60 & 0.30 & -0.35 \\
SVK & 0.52 & -2.01 & 0.29 & -1.97 \\
JPN & -0.05 & 0.05 & -0.01 & 0.02 \\
TUR & 0.45 & -0.45 & 0.10 & -0.67 \\
\hline \hline The table reports values of the wage effects depicted in Figure 7
\end{tabular}


Table A.4: Baseline scenario - wage effects of emigration (\%)

\begin{tabular}{lcccc}
\hline \hline & Young, LS & Young, HS & Old, LS & Old, HS \\
\hline \hline USA & -0.04 & 0.01 & -0.02 & 0.05 \\
CAN & -0.67 & 0.17 & -0.28 & 0.48 \\
AUS & -0.41 & 0.42 & -0.20 & 0.37 \\
NZL & -1.78 & 1.35 & -0.31 & 1.76 \\
GBR & -1.50 & 0.69 & -0.89 & 1.58 \\
IRL & -3.83 & 3.24 & -5.43 & 3.91 \\
DEU & -0.61 & 1.01 & -0.68 & 1.05 \\
AUT & -0.63 & 1.65 & -0.63 & 1.39 \\
CHE & -1.34 & 0.36 & 0.28 & 0.63 \\
FRA & -0.74 & 0.77 & -0.48 & 0.83 \\
BEL & -0.84 & 0.70 & -0.45 & 0.94 \\
NLD & -0.35 & 0.44 & -0.47 & 0.72 \\
LUX & -0.48 & -1.48 & 0.68 & -1.25 \\
ITA & -0.38 & 0.96 & -0.36 & 1.23 \\
ESP & -0.45 & 0.27 & -0.23 & 0.37 \\
PRT & -2.36 & 1.73 & -0.05 & 3.08 \\
GRC & -0.58 & 0.85 & -0.88 & 1.21 \\
DNK & -0.63 & 0.74 & -0.59 & 0.82 \\
SWE & -0.47 & 0.76 & -0.48 & 0.66 \\
NOR & -0.71 & 0.68 & -0.67 & 0.81 \\
FIN & -1.18 & 0.77 & -0.83 & 0.95 \\
CZE & -0.54 & 1.75 & -0.64 & 1.58 \\
HUN & -0.63 & 1.87 & -1.16 & 0.71 \\
POL & -0.73 & 1.69 & -1.56 & 1.83 \\
SVK & -0.98 & 3.54 & -2.04 & 2.01 \\
JPN & -0.11 & 0.05 & -0.07 & 0.13 \\
TUR & -0.18 & 0.24 & 0.06 & 0.63 \\
\hline \hline The table reports values of the wage effects depicted in Figure 8
\end{tabular}


Table A.5: Baseline scenario - total wage effects (\%)

\begin{tabular}{|c|c|c|c|c|}
\hline & Young, LS & Young, HS & Old, LS & Old, HS \\
\hline USA & 8.30 & -2.48 & 2.37 & -8.17 \\
\hline CAN & 17.10 & -7.45 & 10.04 & -13.96 \\
\hline AUS & 13.04 & -13.79 & 8.74 & -16.21 \\
\hline NZL & 5.49 & -0.06 & -0.11 & -4.04 \\
\hline GBR & 16.06 & -15.08 & 12.63 & -18.12 \\
\hline IRL & 3.76 & -0.63 & 0.89 & -2.06 \\
\hline DEU & 6.45 & -5.16 & 2.57 & -10.86 \\
\hline AUT & 6.97 & -10.04 & 2.05 & -17.35 \\
\hline CHE & 18.05 & -16.87 & 14.34 & -20.58 \\
\hline FRA & 10.63 & -11.67 & 5.57 & -15.16 \\
\hline BEL & 5.08 & -1.85 & 1.41 & -7.85 \\
\hline NLD & 11.84 & -10.42 & 4.77 & -15.14 \\
\hline LUX & 11.83 & -18.63 & 7.15 & -21.09 \\
\hline ITA & 8.16 & -19.51 & 3.23 & -18.82 \\
\hline ESP & 13.58 & -9.93 & 10.06 & -18.91 \\
\hline PRT & 9.56 & -19.71 & 7.11 & -15.16 \\
\hline GRC & 9.04 & -11.42 & 6.94 & -16.15 \\
\hline DNK & 9.55 & -10.50 & 5.30 & -11.57 \\
\hline SWE & 6.17 & -8.37 & 3.46 & -6.61 \\
\hline NOR & 7.85 & -6.43 & 4.66 & -7.12 \\
\hline FIN & 6.79 & -2.76 & 4.90 & -8.88 \\
\hline CZE & 4.19 & -14.31 & 3.35 & -9.44 \\
\hline HUN & 8.69 & -18.71 & 7.16 & -14.45 \\
\hline POL & 11.19 & -18.93 & 5.46 & -11.85 \\
\hline SVK & 6.11 & -13.12 & 1.61 & -11.94 \\
\hline JPN & 6.57 & -5.68 & 8.97 & -12.69 \\
\hline TUR & 6.06 & -17.34 & 2.28 & -15.41 \\
\hline
\end{tabular}

$\overline{\overline{\text { The table reports values of the wage effects depicted in Figure } 9}}$ 